\title{
Comportamento de elementos químicos em rochas mineralizadas em ouro na Faixa Seridó, Província Borborema
}

\author{
Ivaldo Rodrigues da Trindade ${ }^{1}$, Jaziel Martins Sá $^{2,3}$ \& Maria Helena de Freitas Macedo ${ }^{2,3}$
}

\begin{abstract}
Resumo A Faixa de Dobramento Seridó, na porção central do Domínio Rio Grande do Norte no NE do Brasil, Província Borborema, contém alguns depósitos de ouro associados a zonas de cisalhamento. Os depósitos de ouro São Francisco e Ponta da Serra estão associados e hospedados nestas zonas de cisalhamento que cortam micaxistos do Grupo Seridó e ortognaisses do embasamento respectivamente. As zonas de cisalhamentos hospedeiras destes depósitos são canais por onde fluidos hidrotermais circularam e provocaram lixiviação com retirada de elementos das litologias e/ou adicionou elementos químicos contidos nesse fluido. As condições de pressão e temperatura foram respectivamente de $3,5 \pm 0,7$ kbar e $574^{\circ} \pm 30^{\circ} \mathrm{C}$ para as rochas originais e milonitizadas. $\mathrm{O}$ estudo petrográfico mostrou que a biotita e o plagioclásio, nos dois depósitos, foram os minerais que tiveram o papel mais importante nas reações químicas. Estas reações mostram a formação de muscovita, cordierita e sillimanita nos micaxistos milonitizados e muscovita e microclinio nos ortognaisses milonitizados. Os estudos de mobilidade de elementos químicos mostraram que durante o evento de deformação/metassomatismo hidrotermal, os elementos Al, Ti e Zr, no geral, permaneceram imóveis. Os elementos mobilizados foram o K e o Rb que aumentaram suas concentrações em todas as faixas de rochas transformadas, enquanto que os elementos $\mathrm{Ca}$, $\mathrm{Na}$ e $\mathrm{Sr}$, diminuíram suas concentrações. Os elementos $\mathrm{Sm}$ e $\mathrm{Nd}$ se comportaram como imóveis no depósito São Francisco, enquanto que no depósito Ponta da Serra, ambos aumentaram suas concentrações. Para a formação de muscovita, além do K liberado pela biotita, também ocorreu a adição desse elemento a partir do fluido hidrotermal. Já a perda de $\mathrm{Ca}$ e $\mathrm{Na}$ se deveu à incorporação desses elementos na fase fluida.
\end{abstract}

Palavras-chave: Zonas de cisalhamento, Milonitização, Circulação de fluidos, deformação/metassomatismo hidrotermal, comportamento de elementos químicos.

\begin{abstract}
Chemical elements behaviour in gold mineralized rocks in the Serido Belt, Borborema Province. The Seridó fold Belt, central part of Rio Grande do Norte Domain, Borborema Province, NE Brazil, contain by some gold deposits associated with shear zones. The São Francisco and Ponta da Serra gold deposits are associated to and hosted in shear zones that crosscut the Seridó Group and basement orthogneisses, respectively. These gold-bearing shear zones are channels through where a great volume of hydrothermal fluids circulated and caused leaching and/or chemical precipitation. The pressure and temperature conditions of the original rock and the mylonite are estimated to have been $3.5 \pm 0.7 \mathrm{kbar}$ and $574^{\circ} \pm 30^{\circ} \mathrm{C}$, respectively. Petrographic studies indicate that biotite and plagioclase, in both deposits, were the most important minerals in the chemical reactions. These reactions were responsible for the formation of muscovite, cordierite and sillimanite in the mylonitic mica-schists, and of muscovite and microcline in the mylonitic orthogneisses. The study of chemical element mobility showed that during the event of deformation/hydrothermal metasomatism, $\mathrm{Al}, \mathrm{Na}$ and $\mathrm{Zr}$, (here) stayed immobile. The mobilized elements were $\mathrm{K}$ and $\mathrm{Rb}$ that show increase of the concentration in all transformed rocks, while $\mathrm{Ca}$, $\mathrm{Na}$ and $\mathrm{Sr}$ show decrease of the concentration. The elements Sm and Nd behaved as immobile in the São Francisco deposit, while in the Ponta da Serra deposit, both elements lost mass. Regarding the formation of muscovite, K was liberated by the biotite brakdown and also entered the system via hydrothermal fluids. The loss of the Ca and $\mathrm{Na}$ was due to the incorporation of these elements in the fluid phase.
\end{abstract}

Keywords: Shear zone, Mylonitization, Fluid circulation, deformation/hydrothermal metassomatism, chemical element behaviour.

INTRODUÇÃO Zonas de cisalhamento são condutos por onde pode circular um grande volume de fluidos, que interagem com as rochas hospedeiras provocando lixiviação e/ou adição de elementos químicos modificando a textura e a composição primária das rochas. Entender o comportamento dos elementos químicos nesse ambiente é fundamental para se fazer correções nos dados usados em estudos litoquímicos, geocronológicos e no entendimento da gênese de depósitos minerais associados.

Na última década vários pesquisadores desenvolveram estudos com o objetivo de entender o comportamento dos elementos químicos em ambientes de 
falhas e zonas de cisalhamento (e.g. Kerric 1986, Cox et al. 1987, Selverstone et al. 1991, Legrand \& Magini 1992, Luiz Silva 1995, Streit \& Cox 1998, Luiz Silva 2000, Luiz Silva et al. 2000, Trindade 2000, Trindade et al. 2000, Dantas et al. 2002, entre outros). Os primeiros estudos de mobilidade de elementos químicos, na Faixa Seridó, foram realizados por Legrand \& Magini (1992), onde foi determinado o comportamento de elementos químicos durante a formação de cordierita, andaluzita e estaurolita, nos micaxistos do Grupo Seridó, e na transformação de um augen gnaisse do embasamento em um muscovita quartzito por cisalhamento. Posteriormente Luiz Silva (1995), e Luiz Silva et al. (2000) realizaram estudos de mobilidade de elementos químicos no depósito de ouro São Francisco.

A Faixa Seridó hospeda várias ocorrências de ouro como as de Tapera, Ponta da Serra, Fazenda Simpático, Serra dos Patos e São Fernando, nos municípios de Caicó e de São Fernando, que formam uma espécie de corredor mineralizado, e a ocorrência de São Francisco no município de Currais Novos, todas hospedadas em zonas de cisalhamento.

Neste artigo, mostramos os estudos do comportamento de elementos químicos em rochas metassedimentares e ortoderivadas milonitizadas e mineralizadas em ouro em duas destas ocorrências, os depósitos São Francisco (DSF) em Currais Novos-RN e Ponta da Serra (DPS), em Caicó-RN, respectivamente. Algumas das principais características observadas nas seções delgadas, que indicam a ação de um fluido nas rochas hospedeiras, foram texturas de dissolução mineral, bordas de reação e substituição mineral parcial ou total. Em ambos os depósitos, as rochas hospedeiras foram submetidas a processos de transformações semelhantes, porém no domínio da rocha metassedimentar a principal mudança observada em seções delgadas foi textural, enquanto que na ortoderivada foram evidentes as mudanças texturais e composicionais. Com isso, este estudo possibilitou que se confrontassem estas propriedades com o comportamento dos elementos químicos durante a milonitização e circulação de fluidos.

CONTEXTO GEOLÓGICO Os depósitos São Francisco (DSF) e Ponta da Serra (DPS) estão inseridos no Domínio Rio Grande do Norte (DRGN) de Brito Neves et al. (2000), porção NE da Província Borborema de Almeida et al. (1977), (Fig. 1). O embasamento paleoproterozóico da Faixa Seridó, na porção a oeste das rochas supracrustais, foi denominado de Grupo São Vicente por Ebert (inédito), de Maciço Rio Piranhas por Brito Neves (1975), Complexo Caicó por Jardim de Sá $(1978,1994)$. É constituído por uma seqüência de rochas metavulcanossedimentares que inclui rochas metassedimentares grauváquicas e psamíticas, englobando gnaisses diversos, metavulcânicas básicas, andesíticas e anfibolíticas. Esse contexto é intrudido por rochas plutônicas cálcioalcalinas de composição granítica a tonalítica correspondentes aos granitóides $\mathrm{G}_{1}$ de Jardim de Sá et al. (1981). Estas unidades têm idades em torno de 2,15 Ga (Hackspacher et al. 1990, Macedo et al. 1991, Legrand et al.
1991, Jardim de Sá 1994, Legrand et al. 1997).

Os granitóides $\mathrm{G}_{2}$ de Jardim de Sá et al. (1981)

são rochas graníticas a granodioríticas com textura porfirítica ou equigranular transformadas em ortognaises. Jardim de Sá (1994) definiu estas rochas como dominantemente augen gnaisses de afinidade subalcalina (monzonítica e shoshonítica) a cálcio-alcalina potássica, com termos granodioríticos e mais básicos, de afinidade cálcio-alcalina, estes últimos em volume aparentemente subordinado. As idades obtidas pelos método $\mathrm{Rb} / \mathrm{Sr}$ e U/ $\mathrm{Pb}$ por diluição isotópica variam de 1,95 a 2,15 Ga. Estes dados levaram Hackspacher et al. (1990) e Legrand et al. (1997) a sugerir que os granitóides $\mathrm{G}_{1}$ e $\mathrm{G}_{2}$ são representativos do mesmo segmento crustal, com esse último representando o termo mais diferenciado.

$\mathrm{Na}$ porção a leste das rochas supracrustais, o embasamento foi denominado de Maciço São José de Campestre por Dantas et al. (1995 e 1997). São unidades compostas por ortognaisses tonalíticos com intercalações de anfibolito e meta-ultramáficas, ortognaisses e migmatitos diversos, hornblenda sieno-monzogranitos calcio-alcalino. Este maciço contém rochas com idades arqueanas que variam de 2,7 a 3,41 Ga. Circundando as rochas arqueanas, ocorrem unidades paleoproterozóicas, representadas por rochas metaplutônicas variavelmente migmatizadas, que incluem augen gnaisses e ortognaisses com piroxênio (Dantas 1996, e Dantas et al. 1995 e 1997).

As rochas supracrustais da Faixa Seridó constituem o Grupo Seridó, que segundo Jardim de Sá e Salim (1980) é formado por três unidades sendo da base para o topo: Formação Jucurutu, constituída de paragnaisses quartzo-feldspáticos com biotita, tendo óxidos de ferro, muscovita, epidoto, apatita e zircão como minerais acessórios. Subordinadamente ocorrem intercalações de anfibolitos, mármores, quartzitos, micaxistos, calciossilicáticas e formações ferríferas. A Formação Equador é composta por muscovita-quartzitos com variação faciológica para muscovita quartzo-xistos. Também ocorrem horizontes de quartzitos feldspáticos com muscovita, quartzitos ferríferos, paragnaisses e intercalações de metaconglomerados. A unidade de topo é a Formação Seridó, composta por micaxistos diversos, ocorrendo localmente níveis enriquecidos nos aluminossilicatos andaluzita, silimanita e menos freqüentemente cianita, sendo comum a presença de cordierita e por vezes estaurolita. Ocorrem intercalações subordinadas e localizadas de quartzitos, mármore, metavulcânicas, rochas calciossilicáticas e metaconglomerados.

A intrusão dos granitóides brasiliano do tipo $\mathrm{G}_{3}$ de Jardim de Sá et al. (1981) se constitui na mais expressiva atividade ígnea na Faixa Seridó, compreendendo seqüências de composição intermediária à básica mais antiga que se constitui nas suítes de K-dioritos, de afinidade shoshonítica a cálcio-alcalina potássica, e as suítes de granitóides porfiríticos, de afinidade subalcalina/monzonítica e granitóides tardi-tectônicos, representados por tipos sob a forma de diques e stocks de composição granodiorítica, equigranular, fino a médio e pegmatitos homogêneos e heterogêneos zonados. As idades U-Pb em zircão entre 


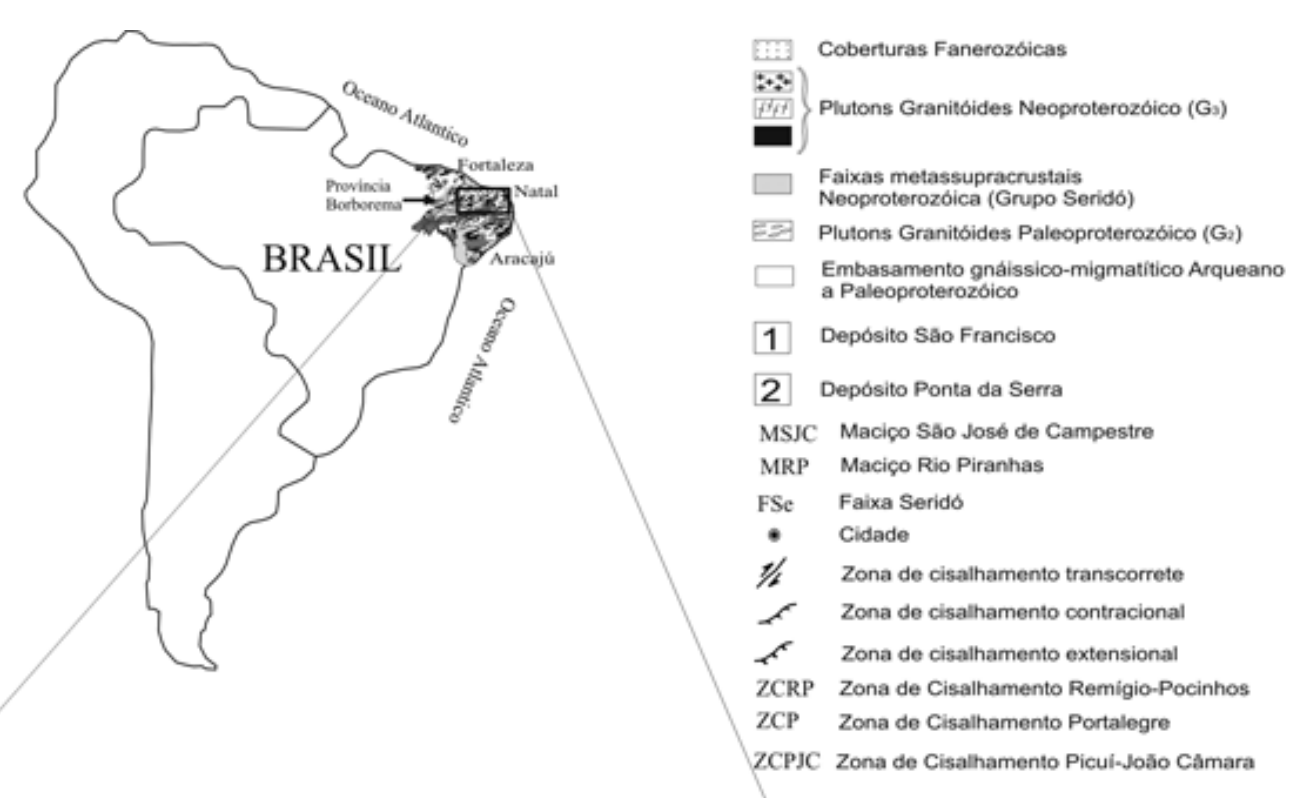

\section{$37^{\circ} 00^{\prime} \mathrm{W} \quad 36^{\circ} 30^{\prime} \mathrm{W}$}

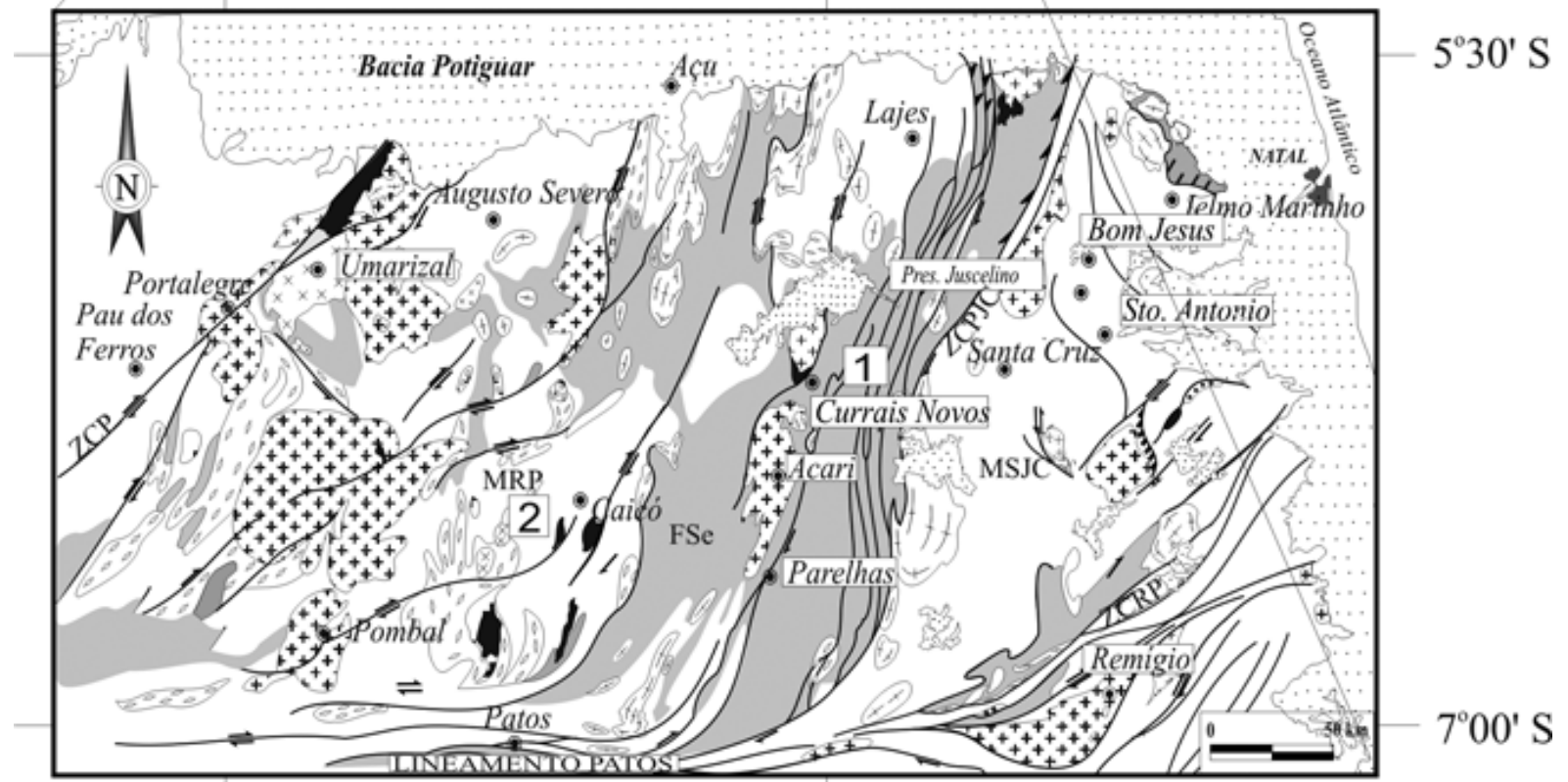

Figura 1 - Arcabouço geológico da Província Borborema e do Domínio Rio Grande do Norte (DRGN), com a localização dos afloramentos (pontos 1 e 2) estudados nesse trabalho. (Adaptado de Jardim de Sá, 1994, Brito Neves 2000 e Dantas et al, 2002).

580 e 550 Ma colocam os corpos de granitóides $\mathrm{G}_{3}$, como neoproterozóico correlatos à orogênese brasiliana.

A idade do Grupo Seridó tem sido discutida nas duas últimas décadas, com preferências para idades paleoproterozóica (ca. $1.9 \mathrm{Ga}$ ) segundo Jardim de Sá (1994). Porém, idades U-Pb em zircões detríticos das Formações Jucurutu e Serídó revelaram valores que colocam o Grupo Seridó com idade neoproterozóica (Van Schmus et al., 2003). Observando a variação isotópica de $\delta \mathrm{C}^{13}$ no Grupo Seridó, Nascimento et al. (2004 e 2007) comparando esta variação com os trends de variação isotópica de $\delta \mathrm{C}^{13}$ existentes na literatura, sugerem que a idade de sedimentação das rochas car- bonáticas do Grupo Seridó, estaria aproximadamente entre 620 a $580 \mathrm{Ma}$, concordando com os valores U-Pb obtidos por Van Schmus et al. (2003).

PROCEDIMENTOS ANALÍTICOS As amostras utilizadas nesse estudo foram coletadas perpendicularmente ao trend estrutural em ambos os depósitos de ouro. O procedimento em laboratório se deu com a preparação mecânica das amostras para fins geoquímicos tomando-se aproximadamente $100 \mathrm{mg}$ de pó da amostras numa fração $<300$ mesh. As amostras foram fundidas com tetraborato de lítio, foram feitas pastilhas fundidas para análise dos elementos maiores e prensadas para os elementos traços. 
A dosagem dos elementos foi realizada no espectrômetro de fluorescência de raios X da marca Phillips modelo PW 2400. Os limites de detecção, de determinação e de quantificação foram para o $\mathrm{Rb}(0,9-1,8-3,0$ ppm) e para o $\mathrm{Sr}$ (1,3-2,7-4,5 ppm), respectivamente.

A preparação de amostra para análise de Sm e de Nd foi realizada segundo o procedimento descrito por Pimentel et al (2002). Aproximadamente $100 \mathrm{mg}$ de pó da amostras foram misturados com uma solução traçadora mista (spike) de ${ }^{149} \mathrm{Sm}-{ }^{150} \mathrm{Nd}$ e a digestão química foi realizada em etapas sucessivas com mistura de $\mathrm{HF}+\mathrm{HNO}_{3} 7 \mathrm{M}$ e com $\mathrm{HCl} 6 \mathrm{M}$ em cápsulas Savillex de teflon. A extração dos elementos terras raras foi realizada em colunas de troca iônica confeccionadas em quartzo, usando resina BIO-RAD AG-50W-X8. A extração do $\mathrm{Sm}$ e do Nd foi realizada em coluna de teflon carregada com resina LN-Spec. A dosagem do Sm e de $\mathrm{Nd}$ foi determinada por diluição isotópica em espectrômetro de massa por ionização termal marca Finnigan MAT-262 multi-coletor do laboratório de geocronologia da UNB. Os valores dos brancos variaram entre 20 e $50 \mathrm{pg}$ para $\mathrm{Sm}$ e entre 50 e $100 \mathrm{pg}$ para $\mathrm{Nd}$.

Para determinarmos a perda ou ganho de massa dos elementos químicos utilizamos o método gráfico isocon desenvolvido por Grant (1986). Em um sistema de eixos cartesianos, quando as concentrações da rocha original são lançadas no eixo $\mathrm{X}$ e as da rocha transformada no eixo Y, as concentrações dos elementos imóveis devem se dispor obrigatoriamente ao longo de uma reta, que é denominada de reta isocon. Já os elementos que foram introduzidos se localizarão acima e os que saíram do sistema, abaixo dessa reta, respectivamente.

Como nem sempre os pontos analíticos definiram um bom alinhamento, optou-se por usar o elemento Al para se determinar a reta isocon, em função do que foi observado nos estudos petrológicos e da grande capacidade desse elemento permanecer imóvel ou de sua pouca mobilidade frente à maioria dos eventos geológicos estudados na Faixa Seridó por outros autores (Legrand \& Magini 1992) e em outras regiões estudadas (Grant 1986; Selverstone et al. 1991; Streit \& Cox 1998).

Os cálculos de diminuição ou aumento da concentração dos elementos químicos foram obtidos com a Equação de Grant (1986) (Equação 1):

$\Delta \mathrm{Ci} / \mathrm{Ci}=\mathrm{C}_{\mathrm{Ei}}{ }^{\mathrm{O}} / \mathrm{C}_{\mathrm{Ei}}{ }^{\mathrm{T}}\left(\mathrm{Ci}^{\mathrm{T}} / \mathrm{Ci}^{\mathrm{O}}\right)-1$.

Esta é a equação fundamental para os cálculos de variação da concentração dos elementos envolvidos em processos de deformação, metamorfismo e metassomatismo hidrotermal, onde: $\Delta \mathrm{Ci} / \mathrm{Ci}$ é a variação de concentração do elemento na rocha transformada, $\mathrm{C}_{\mathrm{Ei}}{ }^{\mathrm{O}}$ é a concentração, na rocha original, de um dos elementos considerados imóveis, $\mathrm{C}_{\mathrm{Ei}}{ }^{\mathrm{T}}$ é a concentração desse mesmo elemento na rocha transformada e $\mathrm{Ci}^{\mathrm{T}} \mathrm{e} \mathrm{Ci}$ são as concentrações do elemento que sofreu variação da concentração nas rochas transformada e original, respectivamente e 1 corresponde a uma variação de massa ou volume de $100 \%$. Usamos a equação simplificada de Grant (1986): $\mathrm{C}_{\mathrm{Ei}}{ }^{\mathrm{O}} / \mathrm{C}_{\mathrm{Ei}}{ }^{\mathrm{T}}-1$ para calcularmos a variação volumétrica da rocha transforma- da com relação a rocha original.

Calculamos as densidades relativas das rochas usando um picnômetro de $50 \mathrm{ml}$, água milli-Q tri-destilada, amostra britada e uma balança química com 6 casas decimais. Os cálculos foram determinados com a equação dada por Dana \& Hurlbut (1969) (Equação 2):

$\mathrm{D}=\left\{\left(\mathrm{P}_{\mathrm{p}+\mathrm{m}}-\mathrm{P}_{\mathrm{p}}\right) /\left(\mathrm{P}_{\mathrm{p}+\mathrm{a}}+\mathrm{P}_{\mathrm{p}+\mathrm{m}}-\mathrm{P}_{\mathrm{p}}-\mathrm{P}_{\mathrm{p}+\mathrm{m}+\mathrm{a}}\right)\right\}$

onde: $\mathrm{P}_{\mathrm{p}}=$ peso do picnômetro vazio, $\mathrm{P}_{\mathrm{p}+\mathrm{a}}=$ peso do picnômetro com água destilada, $\mathrm{P}_{\mathrm{p}+\mathrm{m}}=$ peso do picnômetro com a amostra, $\mathrm{P}_{\mathrm{p}+\mathrm{m}+\mathrm{a}}=$ peso do picnômetro com a amostra e água destilada.

\section{DEPÓSITO SÃO FRANCISCO}

Geologia do Depósito São Francisco (DSF) Os micaxistos auríferos do DSF estão estratigraficamente inseridos na Formação Seridó (Fig. 2) e são representados regionalmente por um granada-biotita xisto feldspático finamente bandado que consideramos como a rocha original (RO) (lâmina MFG-06). Um evento cisalhante transformou progressivamente esta rocha em um cordierita-biotita xisto feldspático, que é a rocha transformada intermediária (Rtint) (lâminas MFG-08 e MFG-14D). Nos locais onde a deformação foi mais intensa, formaram-se zonas de sillimanita-muscovita xisto feldspático milonítico, sendo esta a rocha transformada final (Rtf) e mineralizada (lâminas MFG-14E e MFG-14F).

O granada-biotita xisto feldspático é fino a médio, com uma xistosidade proeminente marcada pelas alternâncias de níveis micáceos com niveis quartzo-feldspáticos. Esses níveis evoluem para remobilizados de quartzo. Nesse último caso, o aspecto passa de xistoso para bandado, concedendo uma maior consistência à rocha, que se mostra mais grossa nestas porções.

O cordierita-biotita xisto feldspático se caracteriza pelo desenvolvimento de nódulos de cordierita que podem chegar a $25 \mathrm{~cm}$ em seu eixo maior, mascarando a xistosidade da rocha. Para evitar que esses nódulos pudessem superestimar os percentuais desses minerais, evitou-se confeccionar lâminas sobre os mesmos.

O silimanita-muscovita biotita xisto feldspático, desenvolvido na zona de mais alta taxa de deformação, é de granulação média a grossa onde se destacam nódulos decimétricos ricos em muscovita e silimanita. Vale salientar que ocorre cordierita e granada, que são minerais típicos das "faixas" anteriores. As zonas de cisalhamento mineralizadas têm atitudes médias $\mathrm{N} 40^{\circ} \mathrm{E} / 60^{\circ}-80^{\circ} \mathrm{SE}$.

Estudos termobarometricos com o termômetro granada-biotita e dos barômetros granada-plagioclásioaluminossilicato-quartzo e granada-plagioclásio-muscovita-biotita realizados por Luiz Silva $(1995,2000)$, indicam que a rocha original e a transformada foram submetidas praticamente às mesmas condições com médias de $\mathrm{P}=3,5 \pm 0,7$ kbar e $\mathrm{T}=574^{\circ} \pm 30^{\circ} \mathrm{C}$.

Petrografia A lâmina estudada da rocha original (RO) foi a MFG-06. Selecionamos 04 lâminas representativas 
$06^{\circ} 10^{\circ} 33^{\prime \prime} \mathrm{S}$

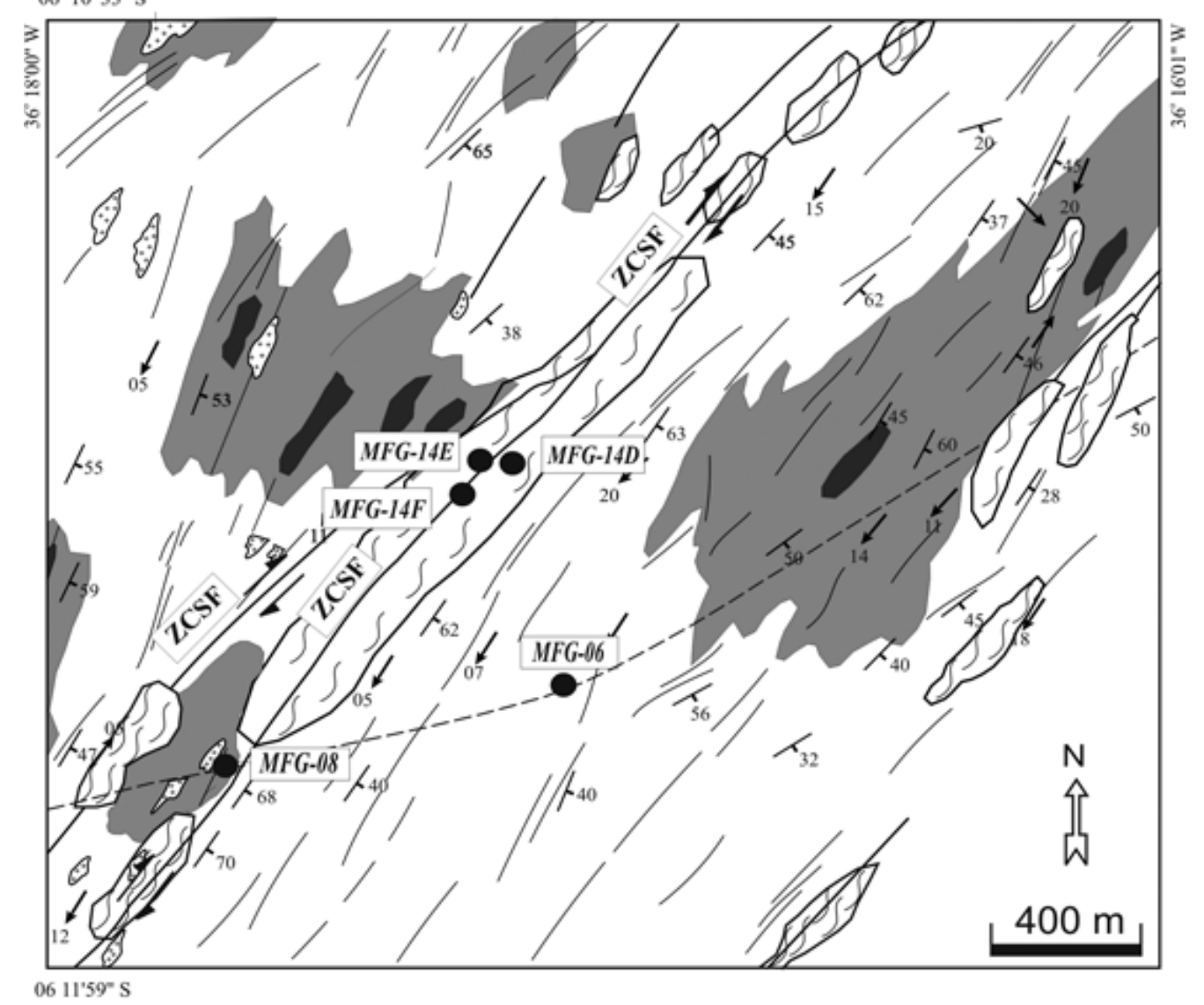

[:: Corpos pegmatíticos.

एJ] Faixa de silimanita-muscovita xisto feldspático.

$\square$ Faixa de andaluzita-codierita-biotita xisto feldspático com halos de estaurolita.

$\square$ Granada-biotita xisto feldspático.

Contato litológico.

I. Zonas de cisalhamento.

\begin{abstract}
Atitude da foliação $\mathrm{S}$.
$\downarrow \quad$ Atitude da lineação de estiramento L.

Traços de foliação $\mathrm{S}$.

Amostras com análises químicas.
\end{abstract}

ZCSF Zonas de cisalhamento São Francisco.

--- Rodovia.

Figura 2 - Mapa metamórfico simplificado do Depósito São Francisco com a localização das amostras. Adaptado de Luiz Silva (1995).

do domínio das transformada. A amostra MFG-08, designada de rocha transformada intermediária-1 (Rtint-1), a amostra MFG-14D, mesmo localizada no interior da zona cisalhada mineralizada (Fig. 2), que é domínio da rocha transformada final (Rtf), em função de sua mineralogia foi considerada como rocha transformada intermediária-2 (Rtint-2). A amostra MFG-14E, classificada como Rtf-1 e a MFG-14F, classificada como Rtf-2.

Os estudos mostraram que em todos os domínios o quartzo é o principal constituinte da matriz. Ocorre como cristais xenomórficos (Figs. 3a e 3b), e também na forma de ribbons, nesse caso nos domínios das Rtf, às vezes com contatos retos poligonais (Fig. $3 \mathrm{c})$. Identificamos duas gerações de biotita, a primeira marcando a foliação milonítica e uma segunda, discordante. No domínio das Rtf, essas biotitas mostram transformação para muscovita (Fig. 3d). O plagioclásio é do tipo oligoclásio com teor médio de $29 \%$ de anortita; está saussuritizado quando associado aos níveis micáceos e nas Rtf ocorre o desenvolvimento de muscovita segundo os planos de clivagem, sendo que apenas na amostra MFG-14D foi identificado carbonato. Também observamos uma segunda geração de plagioclásio, mais albítico. A granada na RO ocorre como cristais com muitas inclusões de quartzo no núcleo, por vezes orientados (Fig. 3b), mostrando bordas sem inclusões e contatos irregulares. Nas Rt ocorre uma geração de cristais de granada com poucas inclusões (Fig. 3e). A cordierita, restrita ao domínio das Rtint, ocorre como porfiroclastos que desviam a foliação milonítica. Mostra textura poiquiloblástica, com destaque para as inclusões ativas de biotita, granada, minerais opacos, turmalina, quartzo e plagioclásio, sendo comum o desenvolvimento de placas de muscovita em sua superfície (Figs. 3f e 3g). A silimanita ocorre como cristais de fibrolita, desenvolvida nos 


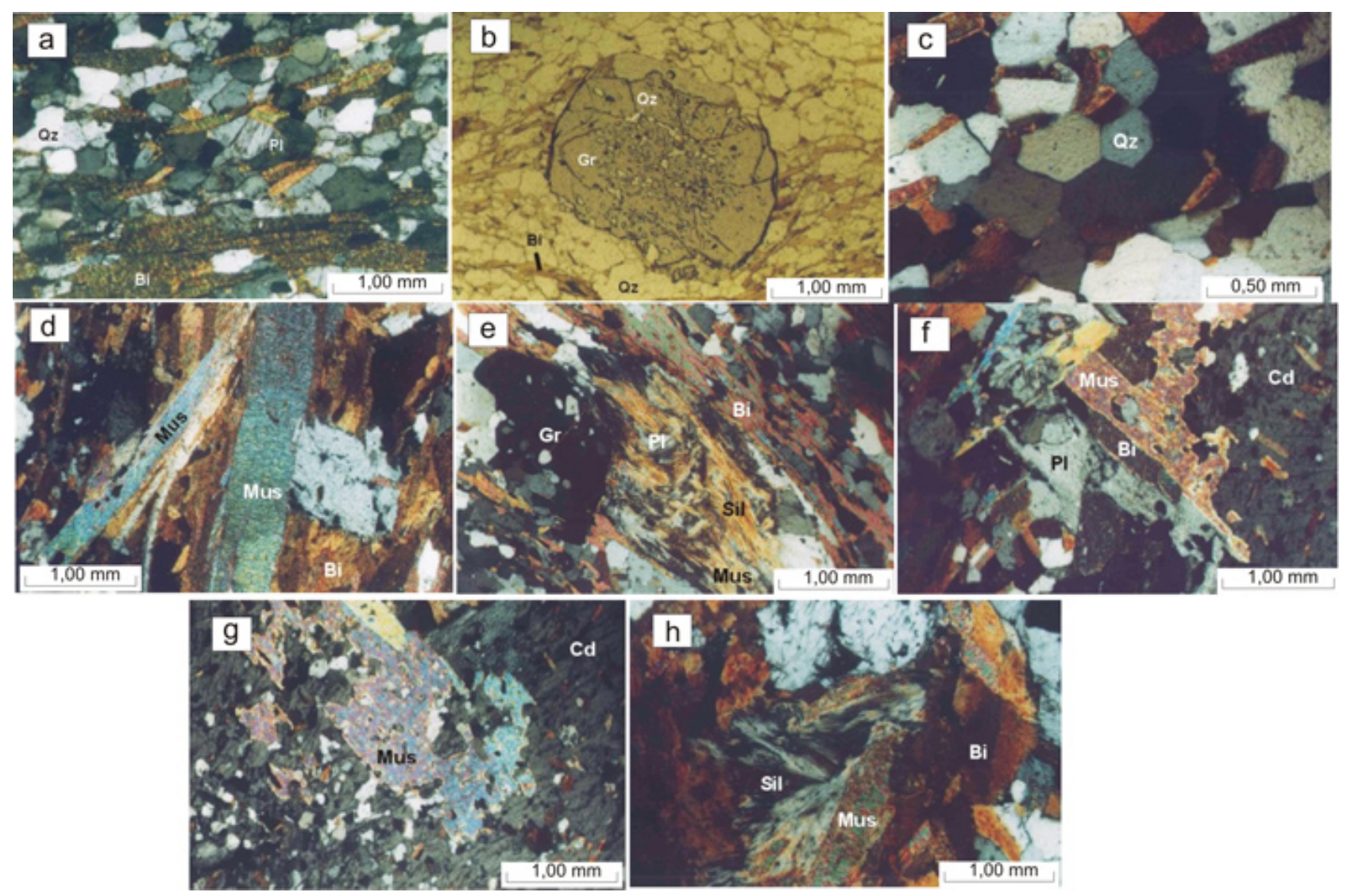

Figura 3 - Fotomicrografias das rochas do depósito São Francisco. Apenas a figura (b) foi fotografada com analisadores paralelos, as demais foram fotografadas com analisadores cruzados. (a) Cristais de plagioclásio (Pl) saussuritizado associado a quartzo (Qz) e biotita (Bt) na rocha original (MFG-06). (b) Cristais de granada (Gr) com sobrecrescimento nas bordas e inclusões de quartzo (Qz). (c) Cristais com contatos retos poligonais evidenciando recristalização estática na amostra da rocha transformada intermediária - 2 (MFG14D). (d) Placas de muscovita (Mus) gerada a partir da biotita (Bt), amostra MFG-14D. (e) Desenvolvimento de silimanita (Sil) na forma de fibrolita gerada a partir da biotita (Bt) e plagioclásio (Pl), amostra MFG-14D. (f) Inclusões de plagioclásios (Pl) e desenvolvimento de muscovita (Mus) tardia em cristais de cordierita (Cd), amostra MFG-14D. (g) Placas de muscovita (Mus) corroída em cristais de cordierita (Cd), amostra MFG-14D. (h) Cristais de cordierita (Cd) e biotita (Bt), amostra MFG-14D.

planos de clivagem da muscovita e da biotita (Fig. 3e) e no contato desta com a cordierita. Também observamos cristais formados a partir da transformação de biotita e plagioclásio (Fig. 3h).

Luiz Silva (2000) determinou a composição das principais fases mineralógicas do DSF com base em estudos de microssonda. A partir dos aspectos texturais e mineralógicos observados em lâminas e das composições das fases apresentadas por Luiz Silva (2000), sugerimos algumas reações para a formação de minerais nas Rt, a partir das equações (no primeiro membro estão os minerais que participaram como reagentes e no segundo membro os minerais produtos) (Equação 3 a 8$)$ :

Biotita $^{(1)}+$ Plagioclásio $^{(1)}+$ Fluido $\leftrightarrow$ CoR-

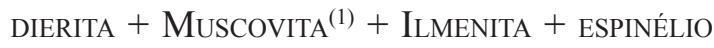
+ QUARTZO + FLUIDO

$\mathrm{K}(\mathrm{Fe}, \mathrm{Mg})_{3} \mathrm{TiAlSi}_{3} \mathrm{O}_{10}(\mathrm{OH})_{2}+\left[6 \mathrm{NaAlSi}_{3} \mathrm{O}_{8}+\right.$ $\left.\mathrm{CaAl}_{2} \mathrm{Si}_{2} \mathrm{O}_{8}\right]+\left[8 \mathrm{H}^{+}+3 / 2 \mathrm{O}_{2}\right] \leftrightarrow$
$\mathrm{FeMg}_{2} \mathrm{Al}_{4} \mathrm{Si}_{5} \mathrm{O}_{18}+\mathrm{KAl}_{3} \mathrm{Si}_{3} \mathrm{O}_{10}(\mathrm{OH})_{2}+\mathrm{FeTiO}_{3}$ $+\mathrm{MgFeAl}_{2} \mathrm{O}_{4}+15 \mathrm{SiO}_{2}+\left[4 \mathrm{H}_{2} \mathrm{O}+6 \mathrm{Na}^{+}+\right.$ $\left.\mathrm{Ca}^{++}\right]$

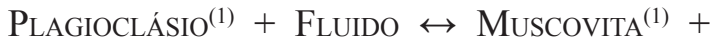
Plagioclásio ${ }^{(2)}+$ Calcita + Quartzo $\left[7 \mathrm{NaAlSi}_{3} \mathrm{O}_{8}+3 \mathrm{CaAl}_{2} \mathrm{Si}_{2} \mathrm{O}_{8}\right]+\left[\mathrm{K}^{+}+\mathrm{H}_{2} \mathrm{O}+\right.$ $\left.\mathrm{CO}_{2}\right] \leftrightarrow \mathrm{KAl}_{3} \mathrm{Si}_{3} \mathrm{O}_{10}(\mathrm{OH})_{2}+\left[6 \mathrm{NaAlSi}_{3} \mathrm{O}_{8}+\right.$ $\left.2 \mathrm{CaAl}_{2} \mathrm{Si}_{2} \mathrm{O}_{8}\right]+\mathrm{CaCO}_{3}+2 \mathrm{SiO}_{2}+\mathrm{Na}^{+}$

Muscovita $^{(1)}+$ Plagioclásio $^{(1)}+$ Fluido $\leftrightarrow$ Biotita $^{(2)}+$ Silimanita + QuARTZO + Fluido $\mathrm{KAl}_{3} \mathrm{Si}_{3} \mathrm{O}_{10}(\mathrm{OH})_{2}+\left[6 \mathrm{NaAlSi}_{3} \mathrm{O}_{8}+\mathrm{CaAl}_{2} \mathrm{Si}_{2} \mathrm{O}_{8}\right]$ $+3 \mathrm{Fe}^{++}+\mathrm{Mg}^{++} \leftrightarrow \mathrm{KFe}_{3} \mathrm{MgAlSi}_{3} \mathrm{O}_{10}(\mathrm{OH})_{2}+$ $5 \mathrm{Al}_{2} \mathrm{SiO}_{5}+6 \mathrm{Na}^{+}+\mathrm{Ca}^{++}+15 \mathrm{SiO}_{2}+1 / 2 \mathrm{O}_{2}$

Biotita $^{1}+$ Plagioclásio $^{(1)}+$ Fluido $^{\text {a }}$ GraNADA + BIOTITA $^{2}+$ Muscovita $^{(1)}+$ QuARTzo $^{2}$ $\mathrm{K}(\mathrm{Fe}, \mathrm{Mg})_{3} \mathrm{AlSi}_{3} \mathrm{O}_{10}(\mathrm{OH})_{2}+\left[5 \mathrm{NaAlSi}_{3} \mathrm{O}_{8}+\right.$ $\left.\mathrm{CaAl}_{2} \mathrm{Si}_{2} \mathrm{O}_{8}\right]+\left[4 \mathrm{H}^{+}+\mathrm{K}^{+}+\mathrm{Ti}^{4+}\right] \leftrightarrow$ 
$\mathrm{Fe}_{2} \mathrm{Al}_{2} \mathrm{Si}_{3} \mathrm{O}_{12}+\mathrm{KMg}_{2} \mathrm{FeTiAlSi}_{3} \mathrm{O}_{10}(\mathrm{OH})_{2}+$ $\mathrm{KAl}_{3} \mathrm{Si}_{3} \mathrm{O}_{10}(\mathrm{OH})_{2}+11 \mathrm{SiO}_{2}+5 \mathrm{Na}^{+}+\mathrm{Ca}^{++}+$ $\mathrm{Mg}^{++}$

Biotita $^{(1)}+$ Plagioclásio $^{(1)}+$ Fluido $\leftrightarrow$
Biotita $^{(2)}+$ Muscovita
Tita + Fluido
$\mathrm{K}(\mathrm{Fe}, \mathrm{Mg})_{3} \mathrm{AlSi}_{3} \mathrm{O}_{10}(\mathrm{OH})_{2}+\left[8 \mathrm{NaAlSi}_{3} \mathrm{O}_{8}+\right.$
$\left.2 \mathrm{CaAl} \mathrm{Si}_{2} \mathrm{O}_{8}\right]+\left[8 \mathrm{H}^{+}+4 \mathrm{~K}^{+}+3 \mathrm{O}_{2}\right] \leftrightarrow \mathrm{O}_{3}$
$\mathrm{KMg}_{3} \mathrm{FeAl}_{3} \mathrm{Si}_{3} \mathrm{O}_{10}(\mathrm{OH})_{2}+4 \mathrm{KAl}_{3} \mathrm{Si}_{3} \mathrm{O}_{10}(\mathrm{OH})_{2}$
$+16 \mathrm{SiO}_{2}+\mathrm{Fe}_{2} \mathrm{O}_{3}+8 \mathrm{Na}^{+}+2 \mathrm{Ca}^{++}$

Biotita $^{(2)}+$ Fluido $\leftrightarrow$ TURMALINA + QUARTZO + FLuido (Luiz Silva 1995)

$1,7831 \mathrm{~K}_{1,65} \mathrm{Na}_{0} 05\left(\mathrm{Mg} 2{ }_{20} \mathrm{Fe}_{2,44} \mathrm{Mn}_{0,01} \mathrm{Cr}_{0.01}\left(\mathrm{Al}_{3}\right.\right.$, $\left.{ }_{55} \mathrm{Ti}_{0,21}\right)\left(\mathrm{Si}_{5,37}\right)_{20}(\mathrm{OH})_{4}+\left({ }^{20}, 8756 \mathrm{H}^{+}+0,4508 \mathrm{Na}^{+}\right.$ $\left.+0,12 \mathrm{Ca}^{5+3}+2,97 \mathrm{~B}^{+++}+0,0522^{+++}\right) \leftrightarrow$

$\mathrm{K}_{0,01} \mathrm{Na}_{0,54} \mathrm{Ca}_{0,12}\left(\mathrm{Mg}_{1,67} \mathrm{Fe}_{0,84} \mathrm{Cr}_{0,07}\right)$ $\mathrm{Al}_{5,93} \mathrm{O}_{27}(\mathrm{OH})_{4}+3,6452 \mathrm{SiO}_{2}+2,9321 \mathrm{~K}^{+}+$ $2,2528 \mathrm{Mg}^{++}+3,5108 \mathrm{Fe}^{++}+0,0178 \mathrm{Mn}^{++}+$ $0,2845 \mathrm{Ti}^{4+}+4,504 \mathrm{H}_{2} \mathrm{O}$

As características observadas nas Rt, com relação à $\mathrm{RO}$, foram empobrecimento de plagioclásio, quartzo e granada e o aumento de biotita ${ }^{(2)}$, além da formação de muscovita, silimanita, cordierita, turmalina e, mais raramente, calcita. Os minerais que tiveram participação mais importante nas reações de transformação foram o plagioclásio ${ }^{(1)}$ e a biotita ${ }^{(1)}$. As transformações são evidenciadas por bordas de reações nos contatos envolvendo estes dois minerais. Alguns aspectos como textura de dissolução, textura em atol e esqueletal, além de um aumento de remobilizados de quartzo nas faixas de rochas transformadas, são consistentes com a participação de fluidos nas reações mineralógicas ocorridas durante o evento de cisalhamento. Estes fluidos foram os responsáveis pela liberação e transporte dos cátions envolvidos nas transformações e formação das novas fases mineralógicas.

Nos estudos petrográficos sistemáticos observamos que a variação mineralógica entre a $R O$ e as $R t$ não foram significativas. A biotita ${ }^{(1)}$ e o plagioclásio(1), na maioria das reações minerais, participaram como reagentes. Porém, observamos que estes minerais também ocorrem como produto na zona milonitizada, com recristalização estática sob condições de altas temperaturas, como mostram os contatos poligonais dos cristais e o aumento das dimensões dos constituintes mineralógicos da rocha transformada com relação à rocha original. Observa-se que o plagioclásio ${ }^{(2)}$ é mais albítico.

Todas as reações propostas aqui apresentadas são dos domínios das Rtint e Rtf. Na Rtint a reação mais importante foi a expressa pela equação (3), responsável pela formação de cordierita e biotita ${ }^{(2)}$. A formação da silimanita ocorreu principalmente a partir da reação expressa pela equação (5), e a formação de muscovita é indicativa de que ocorreram as reações retrometamórficas sugeridas pelas equações (3), (4), (6) e (7). A calcita e a granada tardia foram formadas a partir das transformações mostrada nas equações (4) e (6), respectivamente.
No domínio da Rtf, as fases minerais formadas que se sobressaem são muscovita, silimanita e turmalina. Essa última foi formada a partir da reação do quartzo com o fluido rico nos cátions $\mathrm{Na}^{+}, \mathrm{Mn}^{2+}, \mathrm{Fe}^{2+}$, e no anion $\mathrm{F}^{-}$, liberados nas reações anteriores e do boro, segundo mostrado pela equação (8) de Luiz Silva (1995).

As transformações mineralógicas mostram que na $\mathrm{RO}$ a associação granada-biotita indica que a rocha foi submetida a um metamorfismo da fácies xisto verde. $\mathrm{O}$ surgimento de cordierita e silimanita nas faixas das Rt implica em um aumento do gradiente geotérmico, atingindo a fácies anfibolito.

A associação granada-biotita é típica de metamorfismo regional por absorção de calor do ambiente, sendo P e T reflexos do calor da deformação. Nas faixas de Rt o aparecimento de minerais tipomórficos está relacionado a um metamorfismo hidrotermal, com um fluxo contínuo de fluidos, os quais possibilitou o desenvolvimento de cordierita em sítios que tiveram a atuação de uma deformação moderada e a associação com silimanita em sítios de mais alta taxa de deformação. Resultados semelhantes também foram obtidos por Luiz Silva (1995, 2000) e Luiz Silva \& Legrand (1996).

\section{Comportamento geoquímico no Depósito São Fran-}

cisco Os gráficos isocon da figura 4, foram construídos comparando-se os dados químicos da RO com os das Rtint, bem como das rochas de maior grau de milonitização com maior percentual das fases minerais transformadas (ver Tab. 1).

Nos gráficos isocon da figura 4 , onde comparamos sistematicamente as mudanças de volume e de comportamento de elementos químicos que ocorreram progressivamente da rocha encaixante para a zona milonitizada, observa-se que houve aporte de $\mathrm{K} \mathrm{e} \mathrm{Rb}$ enquanto que $\mathrm{Na}, \mathrm{Ca}, \mathrm{Mn}, \mathrm{Sr}$ e voláteis $(\mathrm{PF})$ saíram do sistema. Os elementos $\mathrm{Al}, \mathrm{Ti}, \mathrm{Fe}, \mathrm{Mg}, \mathrm{Sm}$ e $\mathrm{Nd}$ (Fig. 4A) se comportaram como imóveis.

O Si na maioria das vezes aparece na região de diminuição de concentração. A fixação do $\mathrm{Al}, \mathrm{Mg}, \mathrm{Fe}$ e Ti deve-se à formação da cordierita, ilmenita e biotita, no estágio intermediário e de biotita, muscovita e silimanita na zona milonitizada. A fase fluida reagente tinha em sua composição além de $\mathrm{H}^{+}$, também $\mathrm{K}$, que foi adicionado ao sistema como mostram os gráficos isocon (Fig. 4). Esse $\mathrm{K}$ foi fixado nas novas gerações de muscovita e biotita. A saída de $\mathrm{Na}$ e de Ca do sistema é explicada pelo consumo do plagioclásio. Na figura 4D observa-se que K, Na e Ca mostram uma recuperação com relação às rochas anteriores. Isso se deu em função da geração, no estágio final do evento, de biotita que fixou o K e plagioclásio que fixou $\mathrm{Na}$ e $\mathrm{Ca}$ como mostram as observações petrográficas. As variações volumétricas apresentadas nos diagramas isocon, são corroboradas pelas variações das densidades apresentadas pela RO e as Rt mostradas na tabela 1.

O comportamento inicial dos voláteis deve-se ao consumo da biotita para a formação da cordierita e silimanita, liberando suas moléculas de $\mathrm{H}_{2} \mathrm{O}$. O comportamento do elemento $\mathrm{Rb}$ está diretamente ligado ao 

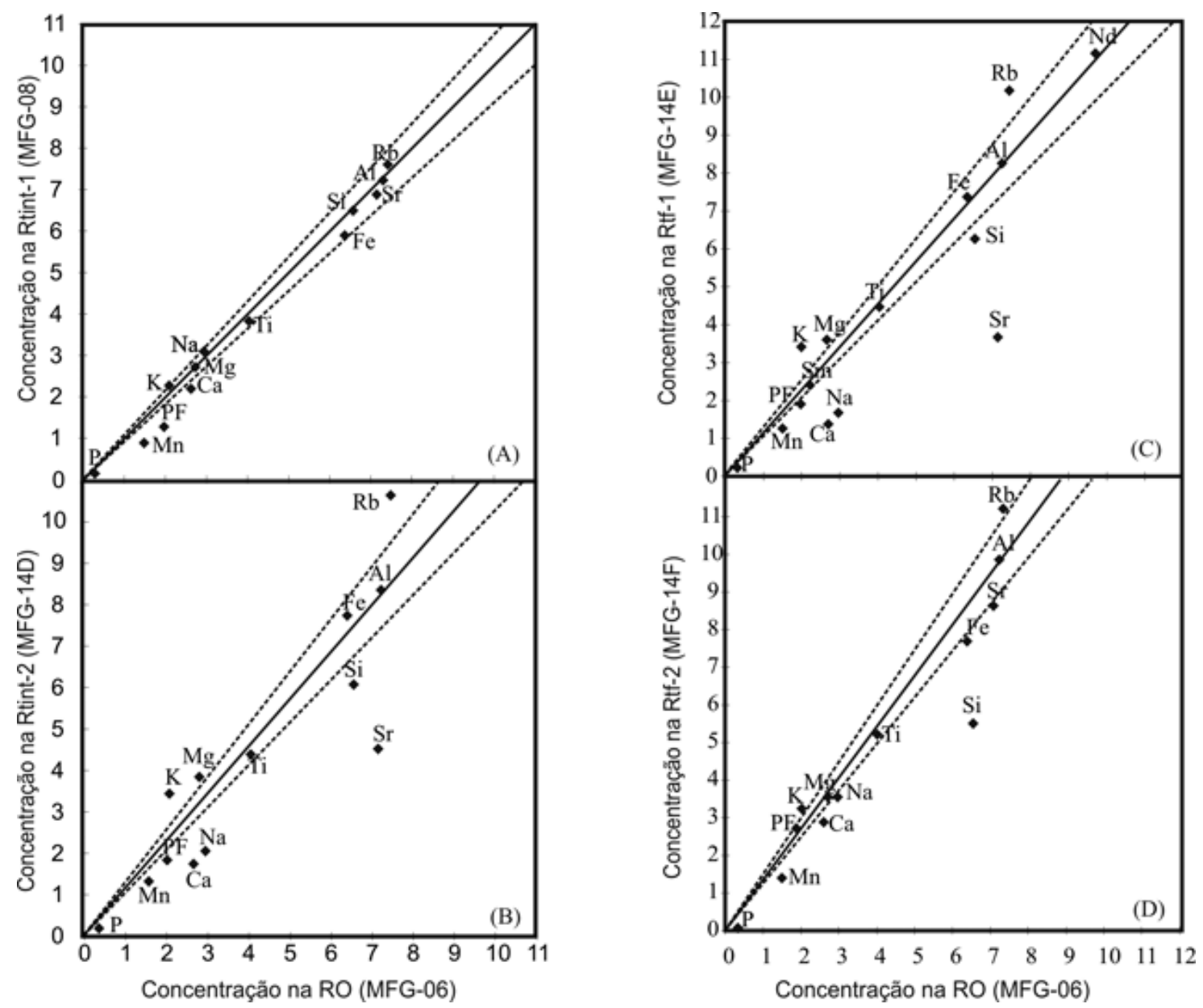

Figura 4 - Gráficos isocon do DSF da Rocha original (RO) Xrochas transformadas intermediárias. Em (A) transformação foi isovolumétrica, em (B) a transformação se deu com perda de volume da rocha de aproximadamente $13 \%$, em (C) com perda de volume da rocha de aproximadamente $12 \%$ e em (D) com uma perda de volume da rocha de aproximadamente $26 \%$.

do $\mathrm{K}$ e do $\mathrm{Sr}$ ao do $\mathrm{Ca}$, uma vez que no ciclo geoquímico estes pares de elementos têm afinidades. Quanto ao Sm e $\mathrm{Nd}$, em função da pouca mobilidade destes durante o metamorfismo e da pequena variação composicional entre as rochas original e milonitizada, permaneceram relativamente imóveis durante o evento.

\section{DEPÓSITO PONTA DA SERRA}

Geologia do Depósito de Ponta da Serra (DPS) Coletamos as amostras do DPS numa cava garimpada (Fig. 5A) e em uma trincheira (Fig. 5B), onde ocorre um exemplo típico da evolução progressiva da transformação tectônica de um augen gnaisse de composição tonalítica em um milonito quartzoso. O ortognaisse apresenta níveis diferenciados de composição granodiorítica. Identificamos pelo menos duas foliações metamórficas: $\mathrm{S}_{2}$ com atitude média $\mathrm{N} 25^{\circ} \mathrm{W} / 30^{\circ} \mathrm{SW}$ e $\mathrm{S}_{3}$ com direção $\mathrm{N} 25^{\circ} \mathrm{W} / 30-65^{\circ} \mathrm{SW}$. Em xenólitos também foi reconhecida uma foliação pretérita correspondente a $\mathrm{S}_{1}$. A mineralização encontra-se hospedada em zonas de cisalhamento $\mathrm{D}_{3}$ (Fig. 5).

$\mathrm{Na}$ área da cava garimpada as amostras MFG22B e MFG-22D são as representantes do domínio da rocha original (RO). Apenas uma amostra do domínio da rocha intermediária (Rtint) foi analisada MFG-22C e na área da trincheira a RO corresponde à amostra MFG$22 \mathrm{G}$, enquanto que no domínio da Rtint foram escolhidas as amostras FJ-14B e a FJ-14C, classificadas como Rtint-1 e Rtint-2 respectivamente, por apresentarem um aumento progressivo na taxa de deformação. Trata-se de um protomilonito, apresentando níveis quartzo feldspáticos descontínuos formando um discreto bandamento com os níveis ricos em muscovita. Em zonas de deformação mais intensa essa rocha é transformada em milonito leucocrático cinza esbranquiçado.

Do domínio da rocha transformada final (Rtf), as duas amostras apresentam algumas características distintas: a amostra FJ-14A é coesa, rósea a esbranquiçada, classificada como Rtf-1; já a amostra MFG-22F é cinza esbranquiçada, classificada de Rtf -2 por apresentar-se num estágio de milonitização mais avançado.

Luiz Silva $(1995,2000)$ determinou as condições de pressão e temperatura nos corpos de minério hospedados em rochas do embasamento, os quais variam de 2,7 a $4,0 \mathrm{kbar}$ e de 560 a $600^{\circ} \mathrm{C}$, respectivamente. Esses valores provavelmente correspondem às 
Tabela 1 - Análises químicas dos elementos maiores (em \% de peso) e traços (em ppm) das unidades litológicas do Depósito São Francisco. Os voláteis estão representados pela PF (Perda ao Fogo).

\begin{tabular}{|c|c|c|c|c|c|c|}
\hline Elem/Am & $\begin{array}{c}\text { MFG-06 } \\
\text { (RO) }\end{array}$ & $\begin{array}{l}\text { MFG-08 } \\
\text { (RTint-1) }\end{array}$ & $\begin{array}{c}\text { MFG-14D } \\
\text { (RTint-2) }\end{array}$ & $\begin{array}{c}\text { MFG-14E } \\
\text { (RTf-1) }\end{array}$ & $\begin{array}{c}\text { MFG-14F } \\
\text { (RTf-2) }\end{array}$ & $\begin{array}{l}\text { Fator de } \\
\text { Correção }\end{array}$ \\
\hline $\mathrm{SiO}_{2}$ & 6,6 & 6,6 & 6,1 & 6,3 & 5,6 & $\mathrm{SiO}_{2} / 10$ \\
\hline $\mathrm{TiO}_{2}$ & 4,0 & 3,9 & 4,4 & 4,5 & 5,3 & $\mathrm{TiO}_{2} \times 5$ \\
\hline $\mathrm{Al}_{2} \mathrm{O}_{3}$ & 7,3 & 7,3 & 8,4 & 8,3 & 9,9 & $\mathrm{Al}_{2} \mathrm{O}_{3} / 2$ \\
\hline $\mathrm{Fe}_{2} \mathrm{O}_{3}$ & 6,4 & 5,9 & 7,7 & 7,4 & 7,7 & \\
\hline $\mathrm{MnO}$ & 1,5 & 0,9 & 1,3 & 1,2 & 1,4 & $\mathrm{MnO} \times 10$ \\
\hline $\mathrm{MgO}$ & 2,7 & 2,8 & 3,9 & 3,6 & 3,6 & \\
\hline $\mathrm{CaO}$ & 2,6 & 2,2 & 1,7 & 1,4 & 2,9 & \\
\hline $\mathrm{Na}_{2} \mathrm{O}$ & 2,9 & 3,2 & 2,1 & 1,7 & 3,6 & \\
\hline $\mathrm{K}_{2} \mathrm{O}$ & 2,1 & 2,3 & 3,5 & 3,4 & 3,3 & \\
\hline $\mathrm{P}_{2} \mathrm{O}_{5}$ & 0,3 & 0,2 & 0,2 & 0,2 & 0,1 & \\
\hline $\mathrm{PF}$ & 2,0 & 1,3 & 1,9 & 1,9 & 2,7 & \\
\hline $\mathrm{Rb}$ & 7,4 & 7,6 & 10,7 & 10,2 & 11,3 & $\mathrm{Rb} / 10$ \\
\hline $\mathrm{Sr}$ & 7,1 & 6,9 & 4,5 & 3,7 & 8,7 & $\mathrm{Sr} / 25$ \\
\hline $\mathrm{Sm}$ & 2,2 & & & 2,4 & & $\mathrm{Sm} / 2$ \\
\hline $\mathrm{Nd}$ & 9,7 & & & 11,2 & & $\mathrm{Nd} / 2$ \\
\hline Densidade & 2,73 & & 2,81 & 2,93 & & \\
\hline
\end{tabular}

Legenda: Elem = Elemento; $\mathrm{Am}=$ Amostra RO = Rocha original, RTint-1 = Rocha intermediária menos transformada, RTint-2 = Rocha intermediária mais transformada, RTf-1 e RTf-2 = Rocha transformada final. O fator de Correção é um valor escolhido para adequar os valores analíticos a escala do gráfico.

condições de cisalhamento dessas rochas.

Petrografia As lâminas estudadas foram confeccionadas a partir das amostras de todos os domínios. O quartzo é constituinte principal da matriz (Figs. 6a, $6 \mathrm{~b}$ e $6 c)$. Alguns cristais mostram contatos retos poligonais, resultado de recristalização estática (Fig. 6d e 6e). No domínio das Rt, aumenta a ocorrência de ribbons orientados segundo a foliação milonítica. A biotita ocorre como palhetas hipidomórficas definindo a foliação da rocha. Palhetas de biotita de uma foliação dobrada (Fig. 6c) por vezes mostram bordas de reação com plagioclásio e muscovita (Fig. 6d).

O plagioclásio é oligoclásio -andesina com An $25-35 \%$. Ocorre como porfiroclastos com bordas cominuídas (Fig. 6a) e como grãos recristalizados que compõem a matriz (Fig. 6d e 6e). Os primeiros estão bastante saussuritizados, com desenvolvimento de muscovita nos planos de clivagem. A muscovita ocorre como palhetas hipidiomórficas a idiomórficas, quando associada à biotita (Fig. 6c) e xenomórficas quando desenvolvida na superfície do plagioclásio (Fig. 6b).
Estas últimas possuem bordas irregulares e superfícies corroídas, preenchidas por quartzo, dando um aspecto de textura em atol. O microclínio é constituinte mineralógico apenas nos domínios das Rt. É intersticial na matriz recristalizada (Fig. 06d e 06e), caracterizando-se como um mineral neoformado, normalmente associado a biotita e muscovita com as quais mostra bordas de reação (Fig. 6d). A granada só foi verificada na amostra MFG-22C. Seus cristais ocorrem com textura de dissolução desviando parcialmente a foliação milonítica (Fig. 6f) ou como cristais de forma arredondada com poucas inclusões de quartzo (Fig. 6g e 6h). O rutilo ocorre como cristais xenomórficos alongados segundo a foliação milonítica.

$\mathrm{Na}$ área do DPS temos um exemplo clássico da transformação de um ortognaisse em uma rocha milonítica rica em muscovita, feldspatos e quartzo. Os estudos petrográficos mostraram que os minerais que tiveram maior participação nas reações, durante o evento de transformação, foram o plagioclásio e a biotita. A química mineral de amostra de área similar a do DPS realizado por Luiz Silva (2000) mostra a composição média das 


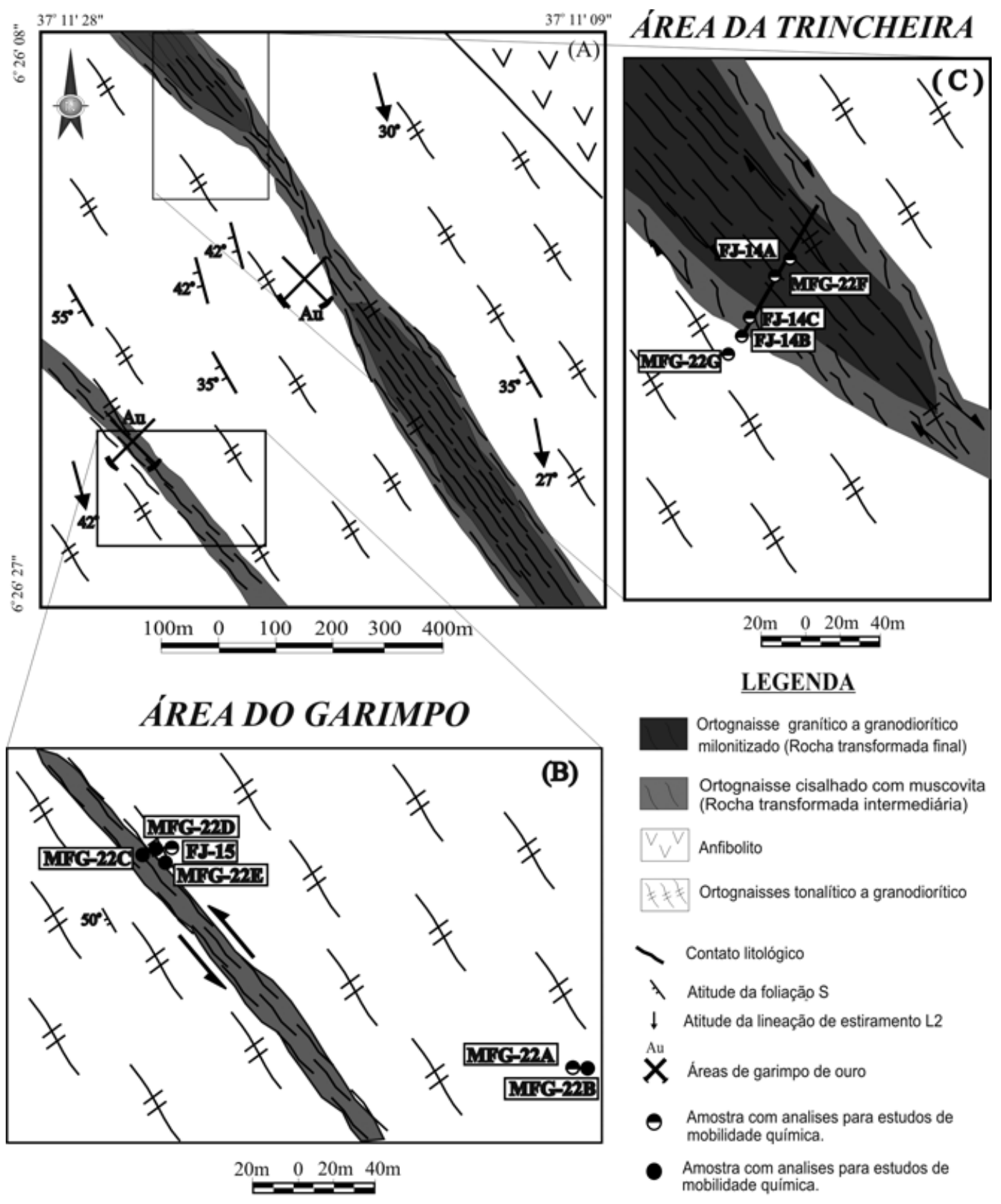

Figura 5 - Mapa geológico simplificado do Depósito de Ponta da Serra (A) com a localização das amostras das áreas do garimpo $(B)$ e da trincheira $(C)$.

principais fases minerais envolvidas nas reações:

Biotita $\left(\mathrm{K}_{1,86} \mathrm{Mg}_{0,66} \mathrm{Fe}_{3,94} \mathrm{Mn}_{0,43} \mathrm{Al}_{3,17} \mathrm{Ti}_{0,44} \mathrm{Si}_{5,37} \mathrm{O}_{20}(\mathrm{OH})_{4}\right)$ Plagioclásio $\left(\mathrm{K}_{0,01} \mathrm{Na}_{0,64} \mathrm{Ca}_{0,34} \mathrm{Al}_{1,43} \mathrm{Si}_{2,60} \mathrm{O}_{8}\right)$

Estudo de inclusões fluidas realizado por Luiz Silva (2000) indica que as rochas mineralizadas sofreram a influência de um fluido inicialmente de natureza aquo-carbônica $\left(\mathrm{X}_{\mathrm{CO} 2} \approx 0,35\right)$, com baixa salinidade $(<$ $8 \%$ em peso de $\mathrm{NaCl}$ equivalente) baixa concentração de $\mathrm{N}_{2}$ e $\mathrm{CH}_{4}$. Posteriormente esse fluido evoluiu para aquoso com salinidade variada o que foi responsável pelas reações fluido-rocha, como evidenciado pelas texturas típicas da ação de fluidos nos constituintes mi- neralógicos das rochas do DPS. Com isso, sugerimos as reações de hidrólise em todos os casos. As principais reações são as dadas pelas equações 9 a 12:

\footnotetext{
Biotita $^{(1)}+$ Plagioclásio $^{(1)}+$ Fluido $\leftrightarrow$

Biotita $^{(2)}+$ Muscovita $^{(1)}+$ QuARTzO $^{+}$Opaco + FLUIDO

$\mathrm{K}(\mathrm{Fe}, \mathrm{Mg})_{3} \mathrm{AlSi}_{3} \mathrm{O}_{10}(\mathrm{OH})_{2}+\left[7 \mathrm{NaAlSi}_{3} \mathrm{O}_{8}\right.$ $\left.+\mathrm{CaAl}_{2} \mathrm{Si}_{2} \mathrm{O}_{8}\right]+\left[6 \mathrm{H}^{+}+3 \mathrm{~K}^{+} 3 / 2 \mathrm{O}_{2}\right] \leftrightarrow$ $\mathrm{KMg}_{3} \mathrm{FeAlSi}_{3} \mathrm{O}_{10}(\mathrm{OH})_{2}+3 \mathrm{KAl}_{3} \mathrm{Si}_{3} \mathrm{O}_{10}(\mathrm{OH})_{2}+$ $\mathrm{Fe}_{2} \mathrm{O}_{3}+14 \mathrm{SiO}_{2}^{3}+7 \mathrm{Na}^{+}+\mathrm{Ca}^{++}$

Plagioclásio $^{(1)}+$ Fluido $\leftrightarrow$ Muscovita + Plagioclásio ${ }^{(2)}+$ QuARTzo + Fluido
} 


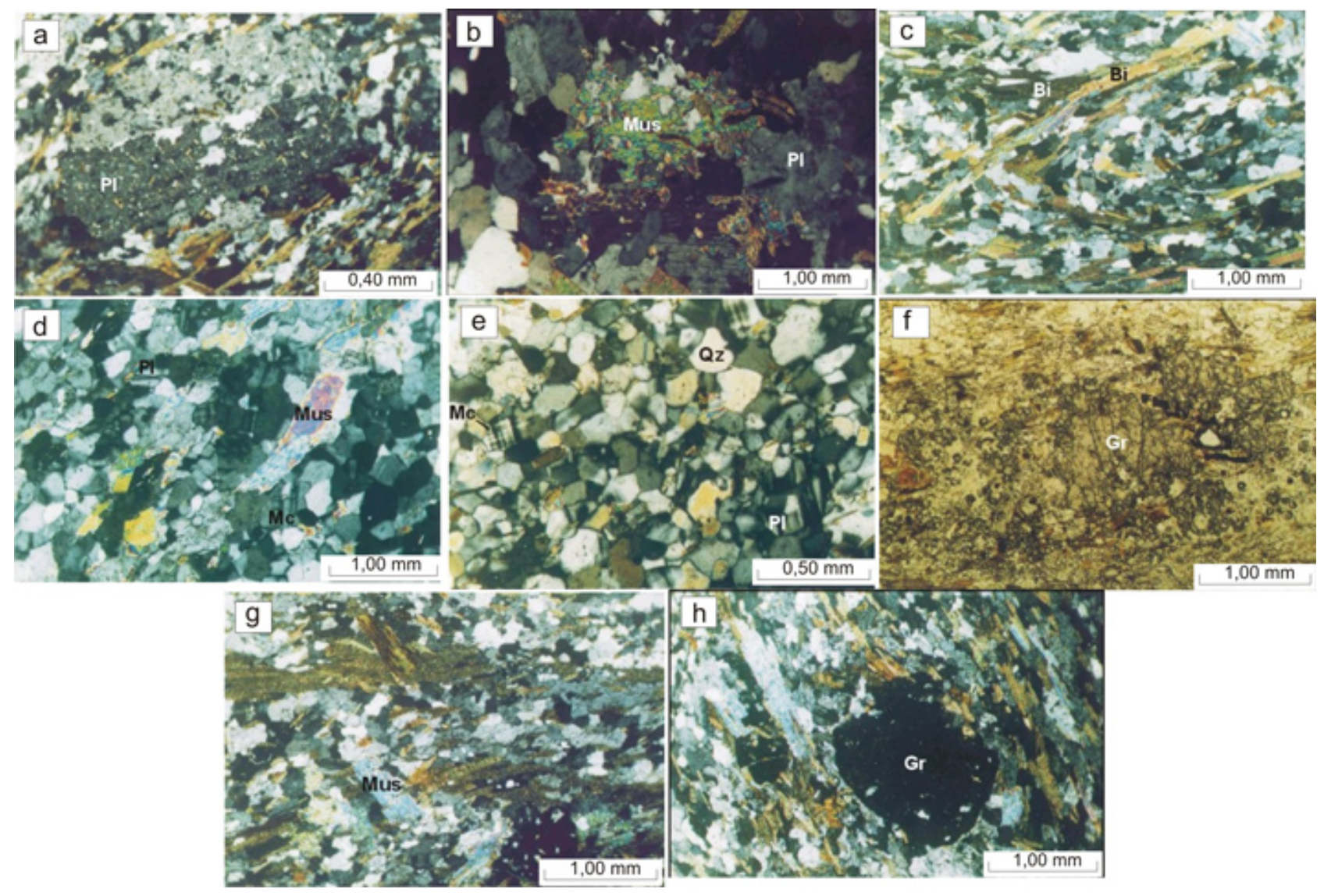

Figura 6 - Fotomicrografias das rochas do Depósito Ponta da Serra. (a) Porfiroclasto de plagioclásio (Pl) com inclusões de biotita (Bt) e quartzo (Qz) na rocha original MFG-22B. (b) Cristais de plagioclásio (Pl) saussuritizado com desenvolvimento de muscovita (Mus) e inclusões de quartzo ( $Q z$ ), na amostra MFG22B. (c) Foliação marcada por biotita dobrada na rocha transformada intermediária MFG-22C. (d) Placa de muscovita (Mus) mostrando borda de reação com microclínio (Mc). Na matriz, cristais de quartzo (Qz) e plagioclásio (Pl) com contatos poligonais, evidenciando recristalização estática, na rocha transformada intermediária FJ-14C. (e) Matriz de quartzo (Qz), microclínio e plagioclásio (Pl) em estágio avançado de recristalização estática, com contatos poligonais na amostra FJ-14C. (f) Granada (Gr) com textura de dissolução, amostra MFG-22C. (g) Cristal de granada (Gr) com forma arredondada desviando a foliação marcada por biotita na amostra MFG-22C.

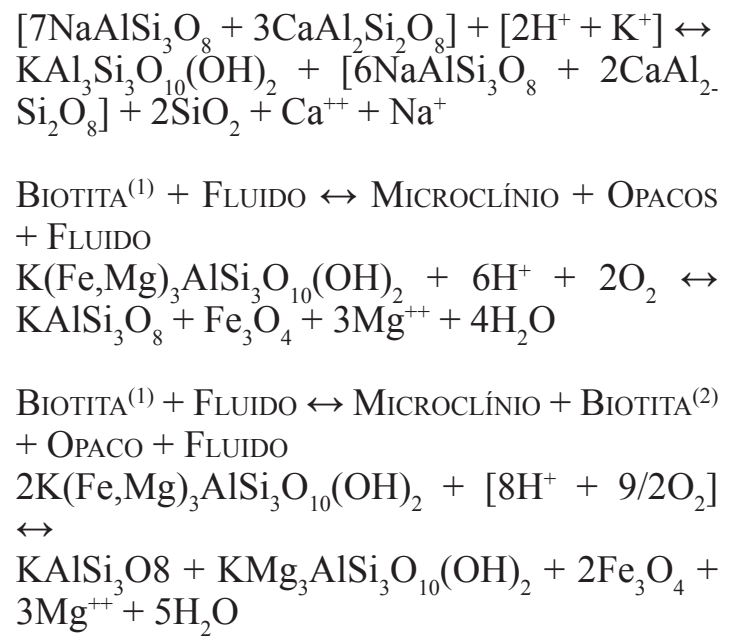

As observações em seções delgadas do DPS revelaram alguns aspectos importantes, quando se comparam as constituições mineralógicas da $\mathrm{RO}$ com os seus produtos de transformações. Observa-se aumento nos conteúdos de quartzo, muscovita e microclínio com a diminuição progressiva no percentual de biotita $^{(1)} \mathrm{e}$ plagioclásio ${ }^{(1)}$. No domínio das Rtint as reações retrometamórficas propostas são: equações (9) e (10), na formação de muscovita ${ }^{(2)}$, plagioclásio ${ }^{(2)}$ e biotita $^{(2)}$ e no domínio da Rtf: equações (11) e (12), na formação de microclínio, caracterizando anatexia. As observações também mostraram que ocorreu um aumento do percentual de muscovita na rocha cisalhada formada tanto a partir da biotita como a partir do plagioclásio sugeridas pelas equações (9) e (10).

Comportamento geoquímico no Depósito Ponta da Serra Para a confecção dos gráficos isocon das figura 7 e 8 utilizamos os dados químicos mostrados nas tabelas 2 e 3. Sm e Nd foram determinadas apenas nas amostras MFG-22B, MFG-22D e MFG-22C da área da cava garimpada, como mostra as tabelas 2 e 3 .

Os gráficos isocon da figura 7A e 7B que comparam individualmente as RO com a Rtint-2, coletada na 
Tabela 2 - Análises químicas dos elementos maiores (em \% de peso) e traços (em ppm) das unidades litológicas da área da cava garimpada.

\begin{tabular}{l|c|c|c|c}
\hline Elem $\backslash$ Am & $\begin{array}{c}\text { MFG-22B } \\
(\text { RO) }\end{array}$ & $\begin{array}{c}\text { MFG-22D } \\
(\text { RO) }\end{array}$ & $\begin{array}{c}\text { MFG-22C } \\
\text { (RTint-2) }\end{array}$ & $\begin{array}{c}\text { F. de } \\
\text { correção }\end{array}$ \\
\hline $\mathrm{SiO}_{2}$ & 6,3 & 6,5 & 6,2 & $\mathrm{SiO}_{2} / 10$ \\
\hline $\mathrm{Al}_{2} \mathrm{O}_{3}$ & 8,2 & 8,0 & 8,2 & $\mathrm{Al}_{2} \mathrm{O}_{3} / 2$ \\
\hline $\mathrm{Fe}_{2} \mathrm{O}_{3}$ & 6,4 & 6,0 & 7,5 & \\
\hline $\mathrm{CaO}$ & 3,0 & 3,1 & 2,6 & \\
\hline $\mathrm{MgO}$ & 1,8 & 1,5 & 2,3 & \\
\hline $\mathrm{Na} \mathrm{O}_{2}$ & 4,1 & 3,9 & 3,4 & \\
\hline $\mathrm{K}_{2} \mathrm{O}$ & 2,3 & 2,3 & 3,3 & \\
\hline $\mathrm{MnO}$ & 1,3 & 1,1 & 1,6 & $\mathrm{MnO} \times 10$ \\
\hline $\mathrm{TiO}$ & 6,7 & 6,5 & 8,4 & $\mathrm{TiO}{ }_{2} \mathrm{X} \mathrm{10}$ \\
\hline $\mathrm{P}_{2} \mathrm{O}_{5}$ & 1,9 & 1,9 & 1,1 & $\mathrm{P}_{2} \mathrm{O}_{5} \mathrm{X} 10$ \\
\hline $\mathrm{PF}$ & 5,5 & 4,3 & 8,8 & $\mathrm{PF} \times 5$ \\
\hline $\mathrm{Rb}$ & 8,1 & 8,4 & 12,1 & $\mathrm{Rb} / 10$ \\
\hline $\mathrm{Sr}$ & 13,5 & 13,3 & 8,9 & $\mathrm{Sr} / 25$ \\
\hline $\mathrm{Sm}$ & 2,7 & 2,6 & 1,3 & $\mathrm{Sm} / 2$ \\
\hline $\mathrm{Nd}$ & 14,4 & 13,7 & 6,9 & $\mathrm{Nd} / 2$ \\
\hline $\mathrm{Densidade}$ & 2,79 & 2,75 & 2,79 & \\
\hline & & & & \\
\hline
\end{tabular}

Legenda: Elem = Elemento; Am = Amostra RO = Rocha original, RTint-2 = Rocha intermediária mais transformada. cava garimpada do DPS, mostraram que, independentemente da amostra de RO utilizada, a transformação se processou com variação volumétrica desprezível, compatível com as densidades relativas observadas na tabela 3 , e o comportamento dos elementos foi o mesmo, salvo pequenas variações nas quantidades de perda ou ganho de alguns elementos. Apenas os elementos Al e Si se comportaram como imóveis durante o evento cisalhante. Os elementos $\mathrm{Fe}, \mathrm{Ti} \mathrm{Mg}, \mathrm{K}, \mathrm{Rb}$ e os voláteis, ficam na região de ganho de massa, enquanto que os elementos $\mathrm{Ca}, \mathrm{Na}, \mathrm{P}, \mathrm{Sr}, \mathrm{Sm}$ e $\mathrm{Nd}$ sofreram diminuição de concentração.

Os gráficos isocon da área da trincheira no domínio das Rtint mostra que a transformação ocorreu com um pequeno aumento de volume das rochas transformadas intermediárias em relação à rocha original, em média $7 \%$, ficando dentro de uma faixa de variação natural da composição das rochas, podendo ser considerada uma transformação isovolumétrica. Essas variações são compatíveis com as densidades relativas apresentadas pelas RO e Rt mostradas nas tabelas 2 e 3 .

Os gráficos mostram que os elementos $\mathrm{Si}, \mathrm{K}$ e $\mathrm{Rb}$ nas Rtint, apresentam aumento da concentração enquanto que $\mathrm{Ti}, \mathrm{Ca}, \mathrm{Sr}, \mathrm{Pe} \mathrm{Fe}$ apresentam perda de massa diminuição da concentração). No domínio da Rtf existem diferenças texturais e composicionais entre as amostras escolhidas como representantes desse domínio. Utilizouse, com isso, as duas Rtf com a RO em gráficos separados (Figs. 8A e 8B), para observar o comportamento dos elementos em ambas durante cisalhamento. A transformação se processou com um pequeno ganho de volume das Rtf com relação a RO, de 4\% em média, podendo

Tabela 3 - Análises químicas dos elementos maiores (em \% de peso) e traços (em ppm) das unidades litológicas da área da trincheira.

\begin{tabular}{|c|c|c|c|c|c|c|}
\hline Elem $\backslash$ Am & $\begin{array}{c}\text { MFG-22G } \\
\text { (RO) }\end{array}$ & $\begin{array}{c}\text { FJ-14B } \\
\text { (Rtint-1) }\end{array}$ & $\begin{array}{c}\text { FJ-14C } \\
\text { (RTint-2) }\end{array}$ & $\begin{array}{l}\text { FJ-14A } \\
\text { (RTf-1) }\end{array}$ & $\begin{array}{c}\text { MFG-22F } \\
\text { (RTf-2) }\end{array}$ & $\begin{array}{c}\text { Fator } \\
\text { correção }\end{array}$ \\
\hline $\mathrm{SiO}_{2}$ & 6,5 & 6,9 & 7,2 & 7,3 & 7,2 & $\mathrm{SiO}_{2} / 10$ \\
\hline $\mathrm{Al}_{2} \mathrm{O}_{3}$ & 7,9 & 7,5 & 7,3 & 7,6 & 7,6 & $\mathrm{Al}_{2} \mathrm{O}_{3} / 2$ \\
\hline $\mathrm{Fe}_{2} \mathrm{O}_{3}$ & 5,8 & 3,7 & 2,2 & 0,6 & 1,7 & \\
\hline Cão & 2,9 & 1,8 & 1,8 & 0,8 & 0,7 & \\
\hline $\mathrm{MgO}$ & 1,4 & 0,7 & 0,3 & 0,2 & 0,5 & \\
\hline $\mathrm{Na}_{2} \mathrm{O}$ & 4,1 & 3,6 & 4,1 & 3,8 & 1,7 & \\
\hline $\mathrm{K}_{2} \mathrm{O}$ & 2,6 & 4,5 & 4,0 & 4,6 & 5,8 & \\
\hline $\mathrm{MnO}$ & 0,6 & 0,3 & 0,3 & 0,1 & 0,1 & $\mathrm{MnO} \times 5$ \\
\hline $\mathrm{TiO}_{2}$ & 6,1 & 5,6 & 4,4 & 4,3 & 5 & $\mathrm{TiO}_{2} \times 10$ \\
\hline $\mathrm{P}_{2} \mathrm{O}_{5}$ & 0,9 & 0,7 & 0,5 & 0,4 & 0,5 & $\mathrm{P}_{2} \mathrm{O}_{5} \times 5$ \\
\hline PF & 0,9 & 0,8 & 0,4 & 1,0 & 1,9 & \\
\hline $\mathrm{Rb}$ & 6,1 & 11,4 & 7,2 & 9,9 & 13,7 & $\mathrm{Rb} / 15$ \\
\hline $\mathrm{Sr}$ & 10,9 & 7,8 & 6,9 & 5,8 & 3,3 & $\mathrm{Sr} / 30$ \\
\hline Densidade & 2,80 & & 2,71 & 2,66 & & \\
\hline
\end{tabular}

Legenda: Elem = Elemento; Am = Amostra RO = Rocha original, RTint-1 = Rocha intermediária menos transformada, RTint-2 = Rocha intermediária mais transformada, RTf-1 e RTf-2 = Rochas transformada final. 


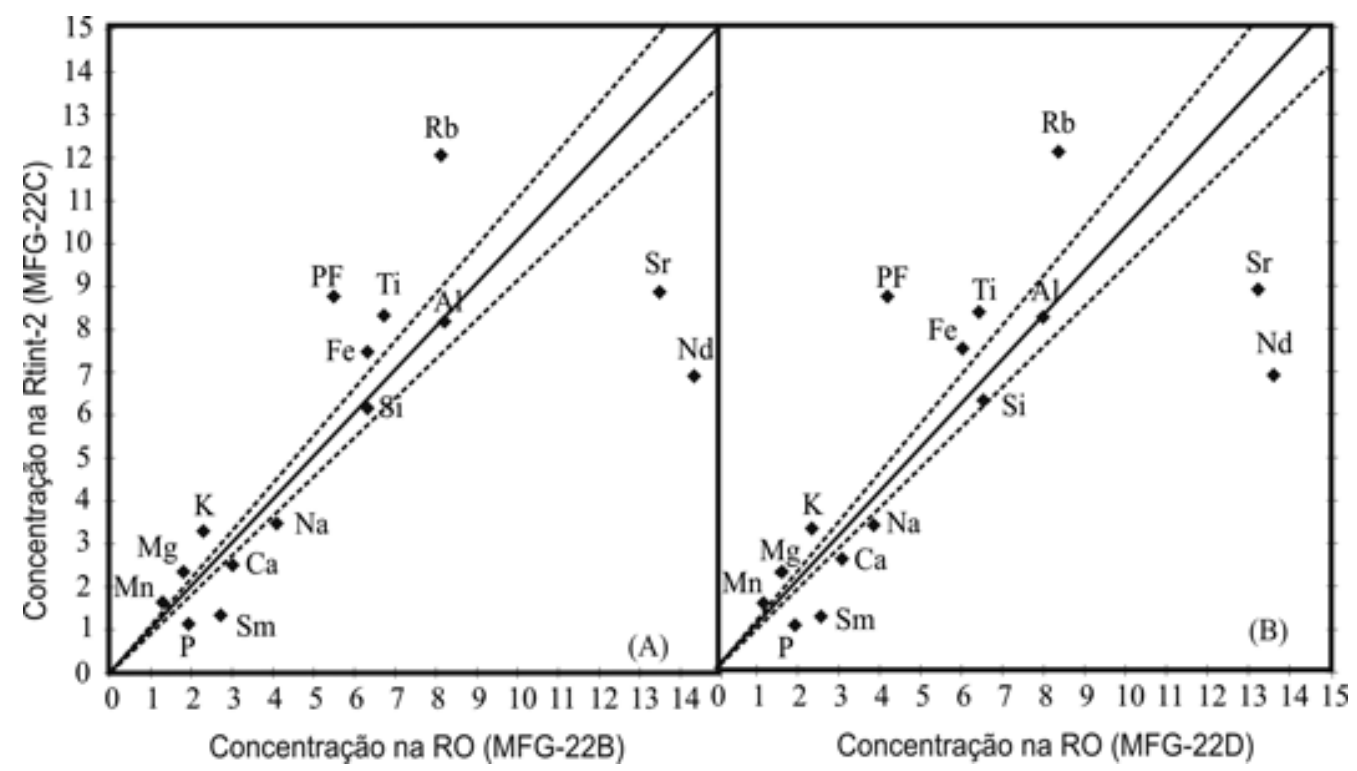

Figura 7 - Gráficos isocon do DPS das Rochas originais $R O X$ rocha transformada intermediária. Em (A) transformação foi isovolumétrica e em (B) a transformação se deu com aumento de volume da rocha de aproximadamente $3 \%$.
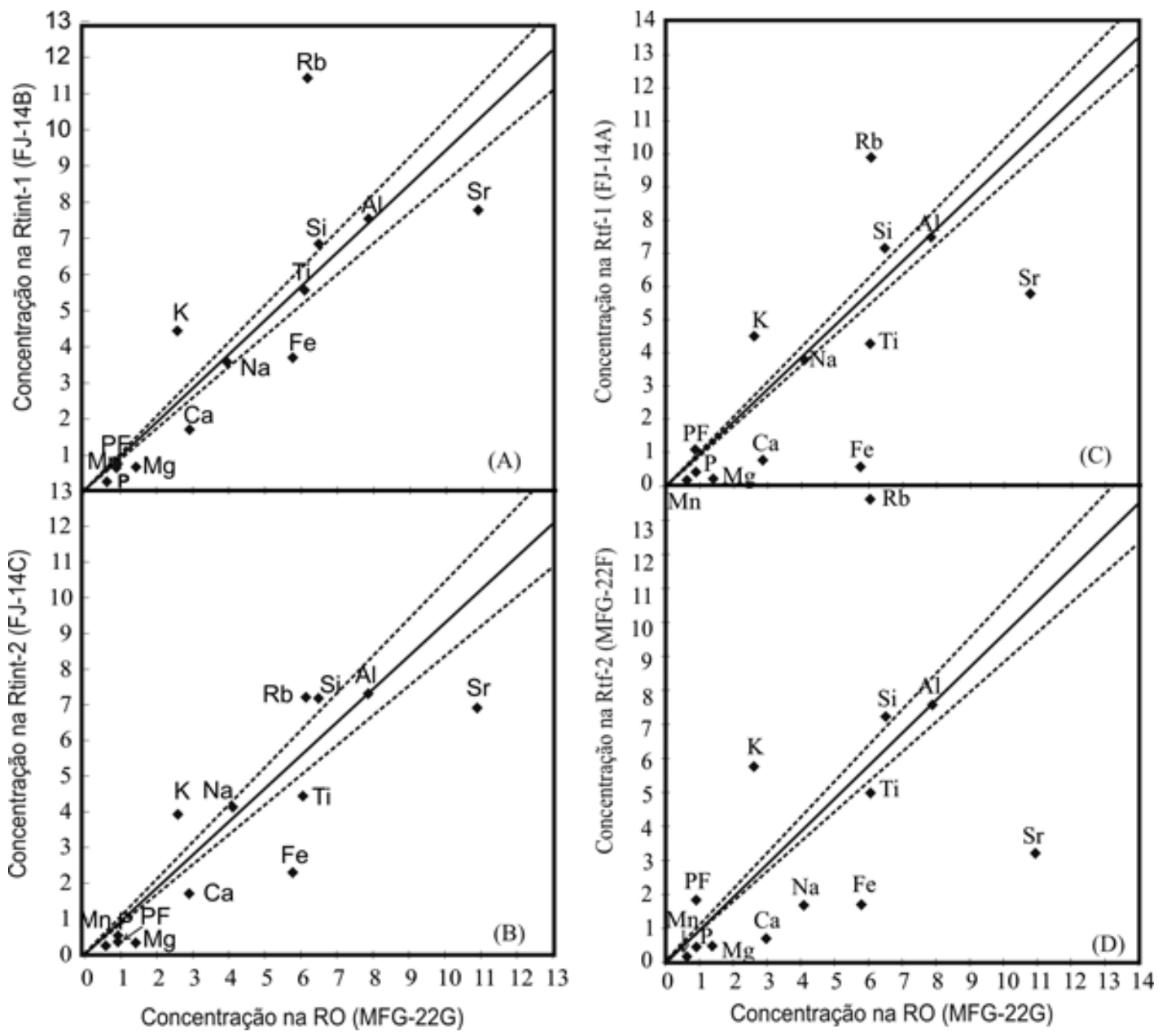

Figura 8 - Gráficos isocon do DPS da Rocha original $R O X$ rochas transformadas intermediária 1 e 2. Com relação a variação de volume das rochas, em (A) transformação ocorreu com aumento de cerca de 5\%, em (B aumento de cerca de 5\%, em (C)e (D) aumento de cerca de $4 \%$. 
ser considerada como uma transformação isovolumétrica. O comportamento dos elementos no domínio das Rtf foi semelhante ao observado no domínio das Rtint, com $\mathrm{Si}, \mathrm{K}, \mathrm{Rb}$ e os voláteis sempre apresentando aumento da concentração, enquanto que $\mathrm{Ti}, \mathrm{Ca}, \mathrm{Mg}$, Sr e Fe diminuição da concentração. O Na na Rtf-1, se comporta como imóvel e na Rtf-2 mostra uma elevada perda de massa com relação à rocha original.

DISCUSSÕES As mineralizações de ouro da Faixa Seridó são epigenéticas formadas por circulação de fluidos hidrotermais, a maioria é controlada por zonas de cisalhamento que funcionaram como canais por onde circularam grandes volumes destes fluidos. A interação dos fluidos com as rochas possibilitou a permuta entre elementos transportados e os elementos formadores dos constituintes mineralógicos da rocha. As evidências de interação fluidorocha são texturas de dissolução em mineral, bordas de reação e substituição parcial ou total de minerais.

A composição inicial do fluido era complexa com $\mathrm{H}_{2} \mathrm{O}, \mathrm{CaCl}_{2}, \mathrm{NaCl} \pm \mathrm{KCl} \pm \mathrm{LiCl} \pm \mathrm{MgCl}_{2} \pm \mathrm{FeCl}_{2}$ passando a ter menor quantidade de $\mathrm{NaCl}$ e $\mathrm{KCl}$ a medida que esse fluido percorria as rochas. As condições de $\mathrm{P}$ e T foram respectivamente de $3,5 \pm 0,7 \mathrm{kbar}$ e $574^{\circ} \pm 30^{\circ} \mathrm{C}$ (Luiz Silva 1995, 2000; Luiz Silva et al. 2000). Essa temperatura é mais elevada do que a obtida por Streit \& Cox (1998) na transformação de um granito em milonito.

Os estudos mostraram que a biotita e o plagioclásio, foram os minerais com participações mais efetivas em todas as reações ocorridas nas rochas mi- lonitizadas, principalmente na formação de muscovita, requerendo aumento na quantidade de $\mathrm{K}$ e, conseqüentemente, liberação de $\mathrm{Na}$ e $\mathrm{Ca}$ para a fase fluida. No depósito São Francisco, porém, a rocha transformada apresenta recristalização destes dois minerais como produto da fase tardia do evento. Esse foi o fator principal para justificar o comportamento do $\mathrm{Fe}$ e $\mathrm{Mg}$ que apresentaram aumento da concentração nas rocha intermediária e imóveis na transformada final (Fig. 9A). Isso é confirmado pela pequena variação composicional entre a rocha original e a transformada final. Em contrapartida, $\mathrm{n}$ depósito Ponta da Serra, esses minerais praticamente desapareceram na rocha transformada final, justificando o comportamento diferenciado dos elementos $\mathrm{Fe}$ e $\mathrm{Mg}$ e a diminuição da concentração de $\mathrm{Na}, \mathrm{Ca}$ e Sr pelo fato de terem sido fixados em nenhuma fase mineral tardia (Fig. 9B). Essa hipótese também pode justificar comportamento dos elementos $\mathrm{Sm}$ e Nd, os gráficos isocon das figuras $4 \mathrm{C}, 7 \mathrm{~A}$ e $7 \mathrm{~B}$ mostram que no primeiro caso $\mathrm{Sm}$ e Nd se comportaram como elementos imóveis e no segundo ambos apresenta consideravel diminuição da concentração. A causa mais provável para o primeiro caso é que os elementos Sm e $\mathrm{Nd}$ tenham sido incorporados nas estruturas da biotita e do plagioclásio recristalizados na rocha transformada final do depósito São Francisco. No caso do depósito Ponta da Serra, o consumo da biotita e do plagioclásio nas reações para a formação de muscovita e microclínio possibilitou a liberação do Sm e Nd para a fase fluida, pois estes são os minerais da rocha original que normal-

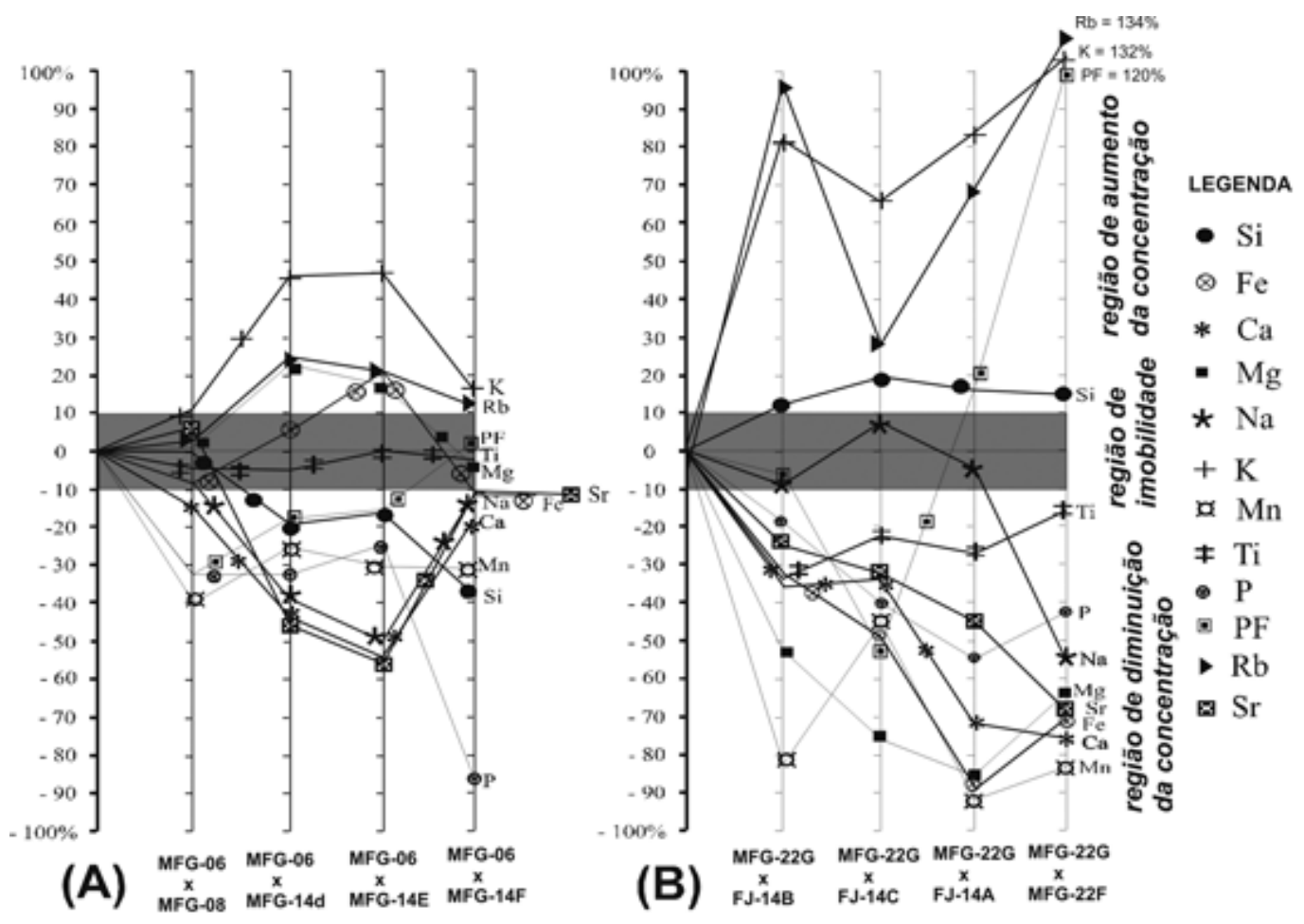

Figura 9 - Integração dos dados de aumento da concentração e diminuição da de elementos químicos obtida a partir dos diagramas isocon das rochas transformadas com relação às rochas originais dos depósitos (A) São Francisco, (B) Ponta da Serra. 
mente possuem as maiores concentrações de Sm e Nd.

Porém, um fato que chama a atenção é que o Sm e o Nd apresentam diminuição de suas concentrações na mesma proporção confirmando o caráter isoquímico desses elementos, indicando que a razão $\mathrm{Sm} / \mathrm{Nd}$ não deve ter sido modificada significativamente, não afetando assim o sistema isotópico, conforme descrito em Trindade (2000), Trindade et al. (2001) e Dantas et al (2002). Já o Rb e o Sr tiveram comportamentos distintos mostrando que o uso dos dados isotópicos desse sistema deve ser visto e interpretado sempre com muita cautela, salvo quando da realização de estudos que comprovadamente mostrem a não mobilidade destes elementos durante os processos geológicos.

CONCLUSÕES Com os resultados que obtivemos, ficou evidente que as propriedades reológicas, composicionais e texturais das rochas submetidas a processos deformacionais e/ou acompanhadas por hidrotermalismo podem exercer influência sobre a mobilidade de elementos químicos, com alguns apresentando maior ou menor capacidade de permanecer no sistema.

O estudo de mobilidade química nos depósitos São Francisco e Ponta da Serra, como visto na figura 9, deixa claro que o $\mathrm{K}$ e o $\mathrm{Rb}$ juntamente com os voláteis, apresentaram aumento da concentração quando se compara a rocha transformada final com a original. Os elementos $\mathrm{Na}, \mathrm{Ca}$ e $\mathrm{Sr}$, em ambas as mineralizações, apresenta diminuição da concentração, enquanto que o $\mathrm{Fe}$ e o Mg na primeira apresenta aumento da concentração, mesmo que na amostra MFG-14F do depósito São Francisco tenham se comportado como imóveis, enquanto que no depósito Ponta da Serra, estes elementos tiveram aumento da concentração. No depósito São Francisco o aumento da concentração dos elementos K e $\mathrm{Rb}$ e diminuição da concentração dos elementos $\mathrm{Na}$, Ca e Sr são bem menores do que o observado no depósito Ponta da Serra como mostra a figura 7. O Sm e o $\mathrm{Nd}$, apesar do número reduzido de amostras analisadas em cada depósito, mostraram-se imóveis no depósito São Francisco e com diminuição da concentração na mesma proporção no depósito Ponta da Serra.

Uma característica marcante nas rochas cisalhadas, hospedeiras das mineralizações, com relação às rochas originais em ambos os depósitos, é o aporte do $\mathrm{K}$, sugerindo que a mineralização está associada a um metassomatismo potássico.

Agradecimentos Os autores agradecem a CAPES pelo apoio financeiro. Ao professor. Márcio M. Pimentel e professora Maria Helena B. M. de Hollanda pelas análises de $\mathrm{Rb}, \mathrm{Sr}, \mathrm{Sm}$ e Nd no Laboratório de Geocronologia da UNB e ao DG-UFRN por ter permitido o uso de seus laboratórios para preparação das amostras para as análises químicas.

\section{Referências}

Almeida F.F.M., Hasui Y., Brito Neves B.B., Fuck R. 1977. Províncias estruturais brasileiras. In: SBG/Simp. Geol. NE, 8, Campina Grande-PB, atas, p.363-391.

Brito Neves B.B. 1975. Regionalização geotectônica do Precambriano nordestino. Tese de Doutoramento, Instituto de Geociências, USP, 198p.

Brito Neves B.B., Santos E.J, Van Schmus W.R. 2000. Tectonic history of the Borborema province, northeastern Brazil. In: Cordani U.G., Milani E.J., Thomaz Filho A., Campos D.A. (eds.) Tectonic Evolution of South America. Int. Geol. Congr., 31 ${ }^{\text {st }}$, Rio de Janeiro, p. 151-182.

Cox S.F., Etheridge M.A., Wall V.J. 1987. The role of fluids in syntectonic mass transport, and localization of metamorphic vein-type ore deposits. Ore Geology Reviews, 2:65-86.

Dana J.R. \& Hurlburt C.S. 1969. Mineralogia Física. In: (eds.) Manual de mineralogia. Ed. Edgar Blucher Ltda., vol I. p.157-170.

Dantas E.L. 1996. Geocronologia U-Pb e Sm-Nd de terrenos Arqueanos e Paleoproterozóicos do Maciço Caldas Brandão, NE do Brasil. Tese de Doutoramento, IGCEUNESP/Rio Claro-SP, 208p.

Dantas E.L., Cordani U., Van Schmus W.R., Hackspacher P.C., Brito Neves B.B., Nutman A.P. 1995. Terrenos Arqueanos e Paleoproterozóicos do Maciço Caldas Brandão na Província Borborema. In: SBG/Simp. Geol. NE, 16, Recife, atas, 14:319-342.

Dantas E.L., Hackspacher P.C., Van Schmus W.R., Brito
Neves B.B. 1997. Arcabouço crono-estratigráfico do Maciço Caldas Brandão-RN- Província Borborema-NE do Brasil. In: SBG/Simp. Geol. NE, 17, Fortaleza, atas, 15:20-23.

Dantas E.L., Hackspacher P.C., Legrand J.M. 2002. Sistema Sm$\mathrm{Nd}$ em rocha-total aberto versus fechado: Comportamento isotópico e, zonas de alta deformação. Revista do Instituto de Geociências - USP Série Científica, 2:109-129.

Grant A.G. 1986. The isocon diagram-A simple solution to Gresens'equation for metasomatic alteration. Economic Geology, 81:1976-1982.

Hackspacher P.C., Van Schmus W.R., Dantas E.L. 1990. Um embasamento transamazônico na Província Borborema. In: SBG/Cong. Bras. Geol. 36, Natal, Anais, 6:26832695.

Jardim de Sá E.F. 1978. Revisão preliminar sobre a "Faixa Dobrada Seridó" e eventuais correlatos no Nordeste. Rev. Ciências, UFRN, 1:77-83.

Jardim de Sá E.F. 1994. A Faixa Seridó (Província Borborema, NE do Brasil) e o seu significado geodinâmico na cadeia Brasiliana/Pan Africana. Tese de Doutoramento. Instituto de Geociências, Brasília-DF, UnB, 803p.

Jardim de Sá E.F. \& Salim J. 1980. Reavaliação dos conceitos estratigráficos na região do Seridó (RN-PB). Miner. Metal., 80(421):16-28.

Jardim de Sá E.F., Legrand J.M., McReath I. 1981. Estratigrafia de rochas granitóides na região do Seridó (RNPB), com base em critérios estruturais. Rev. Bras. Geoc., 
11(1):50-57.

Kerric R. 1986. Fluid infiltration into fault zones: Chemical, isotopic and mechanical effects. Pure and applied geophysics, 124:225-268.

Legrand JM., Liegeois J.P., Deutsch S. 1991. Datação U/Pb e $\mathrm{Rb} . \mathrm{Sr}$ das rochas precambrianas da região de Caicó Reavaliação da definição de um embasamento arqueano. In: SBG/Simp. Geol. NE, 14, Recife, Atas, p. 276-279

Legrand J.M. \& Magini C. 1992. Avaliação das condições termodinâmicas e dos movimentos de matéria na transformação de um granito em um muscovita-quartzito numa zona de cisalhamento. In: SBG/Cong. Bras. Geol., 37, S. Paulo, Anais, v.1. p.433-435.

Legrand J.M., Dantas E.L., Liegeois J.P. 1997. Definição e caracterização do embasamento da porção oeste da Faixa Seridó (Província Borborema, NE-Brasil). In: SBG/ Simp. Geol. NE., 17, Fortaleza, Atas, p. 50-55.

Legrand J.M., Almeida H.L., Souza L.C. 2002. Metmorfismo aloquímico: Caso dos canais térmicos dos micaxisto Seridó (RN). In: SBG, Cong. Bras. Geol., 37, S. Paulo, Anais, v.1. p. 429-430.

Luiz Silva W. 1995. Estudos da interação fluido-rocha na área do Depósito Aurífero São Francisco, Currais Novos-RN: Aspectos estruturais e metamórficos. Dissertação de Mestrado, IGCE/UNESP, Rio Claro, 183p.

Luiz Silva W. 2000. Mineralizações auríferas em veios de quartzo na Faixa Seridó, NE do Brasil: exemplo de depósitos de ouro de fácies anfibolito em faixa móvel proterozóica. Tese de Doutoramento, IGCE-UNESP, Rio Claro, 197p.

Luiz Silva W. \& Legrand J.M. 1996. Termobarometria no Depósito Aurífero São Francisco (RN): evolução metamórfica e caracterização P-T da mineralização. In: SBG/ Cong. Bras. Geol. 39, Salvador, Anais, 3:346-349.

Luiz Silva W., Legrand J.M., Xavier R.P. 2000. Composição e evolução dos fluidos no Depósito Aurífero São Francisco, Faixa Seridó, Província Borborema, Nordeste do Brasil. Rev. Bras. Geoc, 30(4):579-588.

Macedo M.H.F., Jardim de Sá E.F., Peucat J.J., Souza Z.S., Martin H. 1991. Avaliação dos dados geocronológicos do Complexo Caicó(RN) e suas implicações tectônicas. In: SBG/ Simp. Geol. NE, 14, Recife, atas, 12:256-259.
Nascimento R.S.C., Sial A.N., Pimentel M.M. 2004. Chemostratigraphy of medium-grade marbles of the late Neoproterozoic Seridó Group, Seridó Fold Belt, Northeastern Brazil. Gondwana Research, 7(3):731-744.

Nascimento R.S.C., Sial A.N., Pimentel M.M. 2007. C and $\mathrm{Sr}$ isotope systematics applied to Neoproterozoic marbles of the Seridó Belt, Northeastern Brazil. Chemical Geology, 237:191-210.

Pimentel M.M., Spier C.A., Ferreira Filho C.F. 2002. Estudo Sm-Nd do complexo máfico Bacuri, Amapá: Idade da intrusão, metamorfismo e natureza do magma original. Rev. Bras. Geoc., 32:371-376.

Selverstone J., Morteani G., Staude J.M. 1991. Fluid channelling during ductile shearing: transformation of granodiorite into aluminous schist in the Tauem Window, Eastem Alps. J. Metamorphic Geol., 9:419-431.

Streit J.E., \& Cox S.F. 1998. Fluid infiltration and volume change during mid-crustal mylonitization of Proterozoic granite, King Island, Tasmania. J. Metamorphic Geol., 16:197-212.

Trindade I.R. 2000. Estudo Geoquímico e geocronológico $\mathrm{Rb}-\mathrm{Sr}$ e Sm-Nd em zonas de cisalhamento mineralizadas em ouro e suas relações com as rochas encaixantes e geocronológico Sm-Nd em mineralização de Scheelita na Faixa Seridó. Dissertação de Mestrado, PPGG/UFRN, Natal/RN, 125p.

Trindade I.R., Sá J.M., Macedo M.H.F. 2000. Mobilidade química nos micaxistos hospedeiros da Mineralização aurífera de São Francisco, Faixa Seridó, Província Borborema. In: SBG/Simp. Geol. NE, 18, Recife, atas, Boletim 16:118.

Van Schmus W.R., Brito Neves B.B., Williams I.S., Hackspacher P.C., Fetter A.H., Dantas E.L., Babinski M. 2003. The Seridó Group of NE Brazil, a late Neoproterozoic pre-to syn-collisional basin in West Gondwana: insigthts from SHRIMP U-Pb detrital zircon ages and Sm-Nd crustal residence $\left(\mathrm{T}_{\mathrm{DM}}\right)$ ages. Precambrian Research, 127:287-327.

Manuscrito AE 077/2006

Submetido em 24 de janeiro de 2007 Aceito em 24 de junho de 2008 